San Jose State University

SJSU ScholarWorks

Doctoral Projects

Master's Theses and Graduate Research

Spring 5-2016

\title{
Therapeutic Listening Communication in Children with Autism and Hyperacusis
}

Jennifer Margaret Hughes

California State University, Northern California Consortium Doctor of Nursing Practice

Follow this and additional works at: https://scholarworks.sjsu.edu/etd_doctoral

Part of the Maternal, Child Health and Neonatal Nursing Commons, Other Nursing Commons, and the Pediatric Nursing Commons

\section{Recommended Citation}

Hughes, Jennifer Margaret, "Therapeutic Listening Communication in Children with Autism and Hyperacusis" (2016). Doctoral Projects. 42.

DOI: https://doi.org/10.31979/etd.pmmc-ur2q

https://scholarworks.sjsu.edu/etd_doctoral/42

This Doctoral Project is brought to you for free and open access by the Master's Theses and Graduate Research at SJSU ScholarWorks. It has been accepted for inclusion in Doctoral Projects by an authorized administrator of SJSU ScholarWorks. For more information, please contact scholarworks@sjsu.edu. 


\section{ABSTRACT \\ THERAPEUTIC LISTENING COMMUNICATION FOR CHILDREN WITH AUTISM AND HYPERACUSIS}

Hyperacusis, or auditory hypersensitivity, is defined as abnormally sensitive hearing and in some cases an extreme sensitivity, where normally tolerated sounds are perceived as excessively, even painfully loud. This is a debilitating condition for children with autism, causing activity limitations and participation restrictions, also leading to peer isolation and habitual sound avoidance behaviors.

This research explores a means of modifying the auditory environment of a child with hyperacusis in a safe, effective way for the purpose of improving attention span and facilitating learning. The small pilot study $(n=4)$ was a single-subject, multiple-baseline design, conducted with school-aged children in the special education classroom setting. The researcher and associate have designed, developed, constructed, and safety tested the electronic device used in the study; it combines existing sound therapies of white and pink noise generation, noise cancelling headphones, and receives wireless communication from the teacher(s), in a small, wearable package that allows individual preference in user control of the audio levels.

Research consisted of twelve classroom sessions, 15 to 30 minutes in length, with subjects wearing the device during normal classroom instruction. Some sessions added controlled levels of white or pink noise and some did not. Sensory and behavioral data for each child in the study was captured pre- and post-study from both the caregiver/parent and the teacher using the nationally recognized Sensory Profile $2^{\mathrm{TM}}$ tool. The researcher also observed each session, recording qualitative data about student behaviors and classroom interactions along with the physical aspects of wearing and functioning of the device. 
Study results were compiled and found to be generally favorable; the study subjects overall showed varying amounts of improvement in attentiveness during classroom activity and interaction, while wearing of the device was readily accepted across all participants. Research results indicated where some improvements to the device could be made; teacher and parent comments were all positive and supportive of the concept. This study has shown the device may have a beneficial result toward the research objective and warrants further research on a larger scale.

\section{Jennifer Margaret Hughes}

May, 2016 
This page intentionally left blank 


\title{
THERAPEUTIC LISTENING COMMUNICATION IN CHILDREN WITH AUTISM AND HYPERACUSIS
}

\author{
by \\ Jennifer Margaret Hughes
}

\begin{abstract}
A project
submitted in partial

fulfillment of the requirements for the degree of

Doctor of Nursing Practice

California State University, Northern Consortium

Doctor of Nursing Practice
\end{abstract}

May 5, 2016 


\section{APPROVED}

For the California State University, Northem Consortium Doctor of Nursing Practice:

We, the undersigned, certify that the project of the following student meets the required standards of schelarship, format, and style of the uniyersity and the student's graduate degree program for the awarding of the doctoral degree:

Jenuifer Margaret Hughes

\section{Project Author}

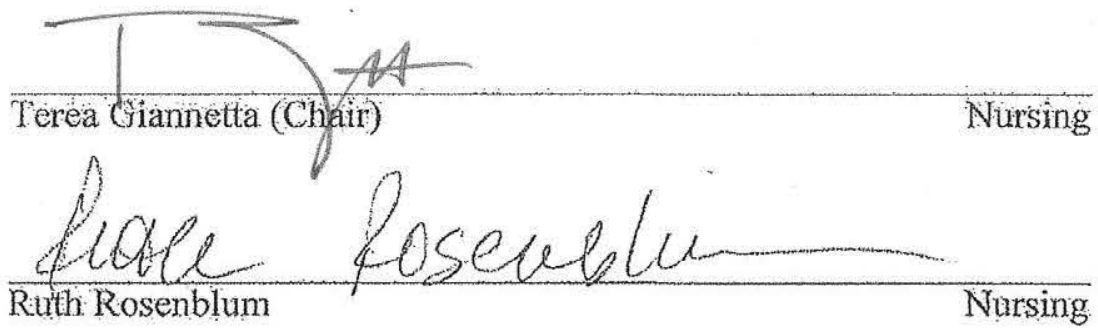

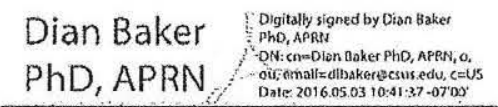

Dian Baker 


\section{AUTHORIZATION FOR REPRODUCTION}

\section{OF DOCTORAL PROJECT}

$\mathrm{X}$

I grant permission for the reproduction of this project in part or in its entirety without further authorization from me, on the condition that the person or agency requesting reproduction absorbs the cost and provides proper acknowledgment of authorship.

Permission to reproduce this project in part or in its entirety must be obtained from me.

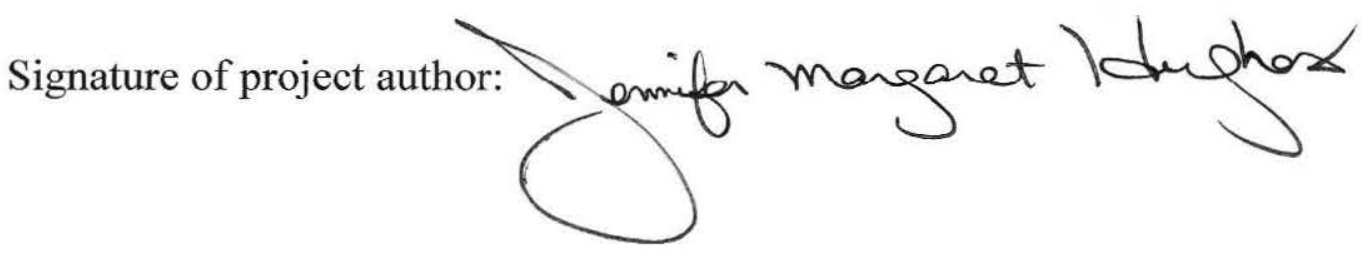




\section{ACKNOWLEDGMENTS}

I would like to acknowledge my family in support of attaining this degree and culmination of this project, particularly my husband Ken Hughes. Full and heartfelt acknowledgement goes to Ken for his vision and engineering design of the Therapeutic Listening Communication device, unwavering support and encouragement. Thank you to our daughters, Heather and Megan for your listening ears and encouragement during this process.

Special thanks to my chairperson and longtime colleague Dr. Terea Giannetta, adviser Dr. Ruth Rosenblum and committee member Dr. Dian Baker for their professional guidance. Thank you to the faculty of the California State University Northern California Consortium Doctor of Nursing Program and to my peers for their support during this process. 


\section{Table of Contents}

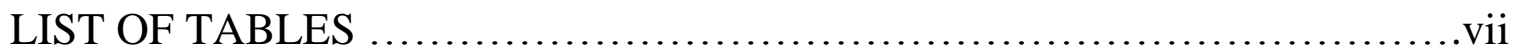

LIST OF FIGURES ......................................................ii

CHAPTER 1: INTRODUCTION........................................ 9

Children with Autism Spectrum Disorder and Auditory Hyperacusis............9

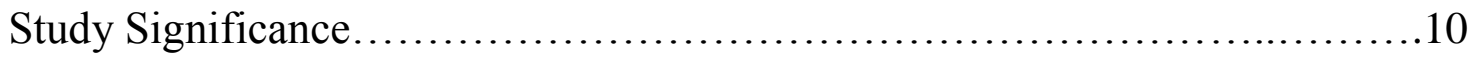

Theoretical Framework: Roy's Model of Adaptation ..........................13

Assumptions........................................................... 14

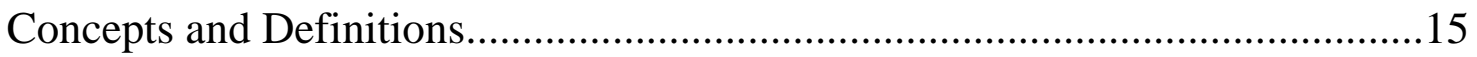

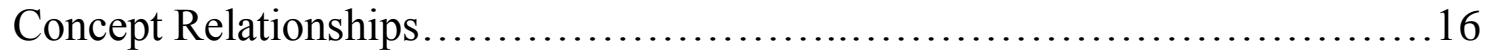

Theory Applicability to Project Population and Setting.......................18

Theory Relevance to DNP Project.........................................19

CHAPTER 2: REVIEW OF THE LITERATURE..........................21

Autism Spectrum Disorder and Hyperacusis.............................21

Impact of Hyperacusis and Learning ....................................23

Hyperacusis Treatment Modalities......................................23

Cognitive Behavior Therapy.............................................

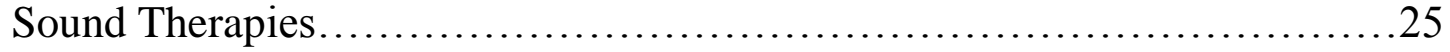

Noise Generation Therapy...........................................27

Noise Cancelling Headphones........................................... 30

FM Wireless Systems............................................... 30

Review of Literature Gaps........................................... 30

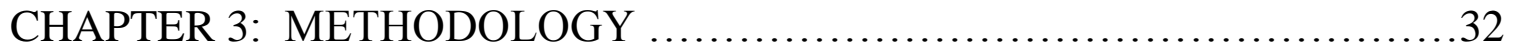

Institutional Review Board Approval......................................32

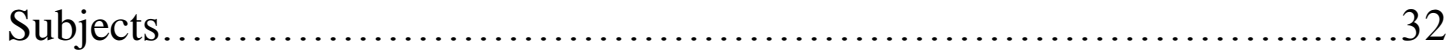


Methods............................................................... 33

Dunn's Sensory Processing Framework.................................36

Interpretation of Sensory Profile $2^{\mathrm{TM}}$ Scoring results....................37

Potential Benefits/Risks...........................................41

Precautions Taken to Minimize Risk...................................42

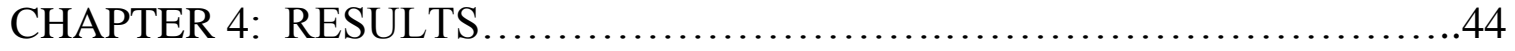

Data Interpretation................................................ 44

Overall Descriptive Analysis........................................46

Individual Interpretation of Findings..................................49

Student F1................................................49

Student F2....................................................52

Student M1 .................................................55

Student M2 ...............................................57

CHAPTER 5: OUTCOMES AND CONCLUSIONS ...........................59

Discussion and Observations........................................60

Study Limitations/Recommendations.................................61

Conclusion ............................................................63

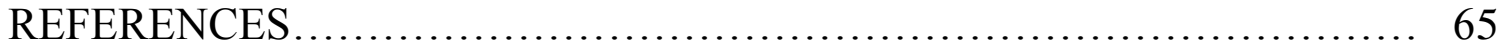

APPENDICES:

APPENDIX A. Sensory Profile 2 ${ }^{\mathrm{TM}}$ Category Definitions................72

APPENDIX B. Pearson Products Permission to Copyright Letter.........74 


\section{List of Tables}

Table 3.1 Research Sessions by Student.....................................35

Table 3.2 Sensory Profile 2 ${ }^{\mathrm{TM}}$ Caregiver Questionnaire Scoring Sheet...........39

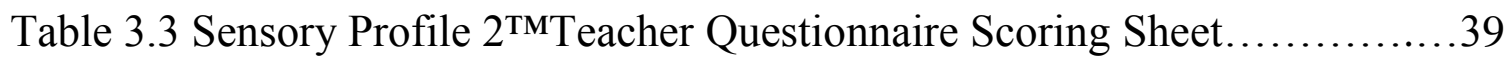

Table 4.1 Student F1 Sensory Profile 2 ${ }^{\mathrm{TM}}$ Composite Scores.....................49

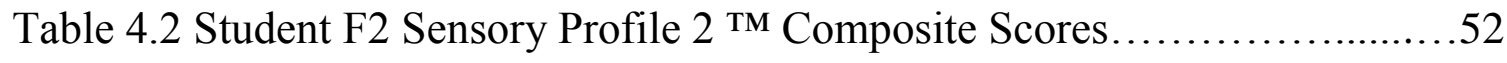

Table 4.3 Student M1 Sensory Profile $2^{\mathrm{TM}}$ Composite Scores.....................55

Table 4.4 Student M2 Sensory Profile $2{ }^{\mathrm{TM} C o m p o s i t e ~ S c o r e s . . . . . . . . . . . . . . . . . . . . .57 ~}$ 


\section{LIST OF FIGURES}

Figure 3.1: Dunn's Sensory Processing Framework.....................................36 


\section{CHAPTER 1: INTRODUCTION}

\section{Children with Autism Spectrum Disorder and Auditory Hyperacusis}

Autism Spectrum Disorder (ASD) is a neurodevelopmental disorder which can range from mild to severe with features such as verbal and nonverbal communication impairments, difficulties in social interactions and concomitant sensory processing disorders. ASD is the broad terminology, which includes individuals identified with pervasive developmental disorder, not otherwise specified (PPD-NOS), autistic disorder (AD), and high-functioning autism (formerly known as Asperger's syndrome). While the sociocultural and medical classification of ASD has greatly changed since the initial identification seven decades ago, common features exist across the spectrum which make these individuals vulnerable to mental health disorders such as anxiety and depression (Duchan \& Patel, 2012; Maloret \& Sumner, 2014).

Auditory hyperacusis is defined as abnormally sensitive hearing with extreme sensitivity to sound, where normally tolerated sounds are perceived as being excessively loud (Gomes, Rotta, Pedroso, Sleifer, \& Danesi, 2004; Juris, Andersson, Larsen, \& Ekelius, 2014 Stiegler \& Davis, 2010). Available literature characterizes hyperacusis as a diminished tolerance to sound with perceptual, psychological and social implications (Aazh et al., 2014; Corbett \& Constantine, 2006; Pienkowski et al., 2014). Statistics suggest $17-20 \%$ of individuals affected with ASD will also have hyperacusis (CDC, 2014; Gomes et al., 2004; Rosenhouse, 2014). According to Lucker (2013), children with ASD and hyperacusis develop self-regulatory patterns to assist them in coping with their external environment and incorporating strategies which may be passive (withdrawal/avoidance) or active (hands over ears/screaming). The goal of sensory 
processing therapy is to provide the tools necessary for the child to adapt to their sensory environment and manage the process of everyday life (Dunn, 2014).

The goal of this project is to explore an effective means for modifying the auditory environment of a child with ASD and hyperacusis in a safe, simple way, for the purposes of improving attention span and facilitating learning. The research questions were:

1. In children with autism and auditory hyperacusis, does application of Therapeutic Listening Communication (TLC), compared to no application of TLC affect attentiveness during educational sessions?

2. In children with autism and auditory hyperacusis, does application of TLC, compared to no application of TLC affect participation during educational sessions?

\section{Study Significance}

Individuals who have hyperacusis report fear and avoidance of work and social activities (Juris, Andersson, Larsen, \& Ekelius, 2014), leading to peer isolation and habitual sound avoidance (Stiegler \& Davis, 2010). Physical characteristics of sound such as spectrum and intensity characterize hyperacusis and the negative reaction they invoke, more than the sound's meaning or context in which it occurred (Aazh et al., 2014). Given that one in 68 children in the United States have been identified as having ASD (CDC, 2014), auditory hypersensitivity is a growing concern for which there are currently limited viable treatment modalities and resources. Investigative studies thus far have focused primarily on the root cause of hyperacusis in children with ASD versus effectiveness of treatment modalities. While there has been much study on possible 
causes of ASD (CDC, 2014), there is scant evidenced-based research applying clinical interventions to treatment of auditory hyperacusis with ASD.

Recent statistics suggest that prevalence rates of ASD have increased annually by 10-17\% in the past few years (U.S. Department of Health and Human Services, 2015). ASD is four to five times more common in males, affecting over three million individuals in the U.S. and additional millions worldwide (CDC, 2014; Duchan \& Patel, 2012; Maloret \& Sumner, 2014). The ten-fold increase in prevalence over the last four decades may be due to improved awareness and improved diagnosis, but this could be only a partial explanation for the worldwide surge in cases of diagnosed ASD. The 2004 U.S. census bureau identified $9 \%$ of families as having a family member with ASD; in 2008, this rate increased to $13 \%$ (U.S. Department of Health and Human Services, 2008). In 2014, the National Health Statistics Report stated the estimated prevalence of ASD was 2.24\%, significantly increased from 2011-2013 data which estimated prevalence rates of 1.25\% (Zablotsky, Black, Maenner, Schieve, \& Blumberg, 2015).

Cultural disparity is an attributable factor, as the highest rate of prevalence is found in multiracial and low-income families (Morrier \& Hess, 2012). ASD is characterized as an integrated model of disability, advocating a combined approach in which the child's social, psychological and spiritual characteristics are incorporated. Effective management of ASD requires a team approach between health, social and educational services working in conjunction with the individual, their family and community (Aazh, Moore, \& Prasher, 2011; Hyche \& Maertz, 2014; U.S. Department of Health and Human Services, 2015). ASD is generally diagnosed by the educational system in contrast to the healthcare system by nature of the identifying characteristics. 
Commonly, once the child enters the educational system and learning disabilities are identified, the healthcare system becomes involved. Cultural and ethnic characteristics factor heavily into access to educational and healthcare systems.

African American and Latino children with ASD are less likely to have a primary healthcare provider than Caucasian children (CDC, 2014; Hallmayer et al., 2011; Magana, Parish, Roderick, Timberlake, \& Swaine, 2012). Caucasian children are also more likely to be diagnosed with ASD than African American or Latino children, with about 1 in 63 Caucasian children, compared to 1 in 81 African American children and 1 in 93 Latino children (CDC, 2014; Frederickson, Acuna, Whetsell, \& Tallier, 2005; Morrier \& Hess, 2012). Cultural disparity is associated with dissatisfaction of care received and a lack of information and referrals provided (Magana, Parish, Roderick, Timberlake \& Swaine, 2012; Morrier \& Hess, 2012). Healthcare disparities may be partly related to language barriers between the provider and client. Magana et al (2012), indicated decreased quality of healthcare has been significantly identified in undocumented immigrants, particularly those whose primary language is other than English. Overall, Caucasian children with disabilities are more likely to be identified and enter both the healthcare and educational systems at a younger age, a disparity which has been found nationwide (Morrier \& Hess, 2012).

While the cause of ASD is not known, potential causes are being investigated. The national symbol of ASD is colored pieces of a puzzle, which demonstrates the various components of identification and understanding of this complex disorder. Each case of ASD is different with wide ranges of symptomology - hence the term on the spectrum. The majority of autism diagnoses appear to be influenced by joint factors of 
ASD risk genes and environmental factors influencing early brain development (Aazh et al., 2014; Hallmayer et al., 2011). A genetic predisposition in the presence of environmental stress appears to increase a child's risk (Duchan \& Patel, 2012; Hallmayer et al., 2011). Other factors, such as both parents being of advanced parental age at the time of conception, maternal illness during pregnancy, fetal oxygen deprivation, reduced prenatal vitamin and folic acid intake, and the role of the immune system have been identified to moderately increase risk in conjunction with genetic predispositions (Hallmayer et al., 2011; Maloret \& Sumner, 2014). The growing incidence of ASD is of concern on many levels; ASD is a lifelong diagnosis with serious implications to our educational, health care, social and economic systems.

\section{Theoretical Framework: Roy's Model of Adaptation}

Sister Callista Roy's Model of Adaptation was influenced by her clinical experiences in pediatric nursing and personal background. The model was initially developed and implemented in 1964 at Mount St. Mary’s College in Los Angeles. In 1970, her first published article, “Adaptation: A Conceptual Framework for Nursing” presented the basic ideas of the conceptual model (Roy, 1970). Over the course of the next several decades, Roy continued to refine and clarify components of the model, publishing several editions of the original text which have been utilized in nursing programs throughout the United States (Roy, 1976). Collaborating with colleagues, significant developments to the model have been published over the last thirty-eight years for the purpose of nursing research, clinical practice and education.

Sister Callista Roy, PhD, RN, FAAN is a Sister of St. Joseph of Carondelet and has been recognized worldwide for her contributions to the profession of nursing. She is 
a professor of nursing at the F. Connell School of Nursing, Boston College, has been involved in nursing education for over 46 years at several prestigious universities in the United States and has been a visiting professor abroad in multiple countries. Dr. Roy is a respected leader in nursing education and research, assisting in the development of Master's and PhD programs in nursing. Dr. Roy is best known for her landmark work developing and applying the Roy's Model of Adaptation to nursing and leadership for knowledge based practice.

Dr. Roy's most recently published book (2014), is focused on evidenced-based practice $(\mathrm{EBP})$ and middle range theory $(\mathrm{MRT})$. Recognizing the need for evolving changes in nursing practice and the gap between nursing knowledge and practice, Dr. Roy was inspired to utilize her vast reservoir of research into application of five middle range theories relevant to current clinical nursing practice. The five MRT's are coping, adapting to life events, adaptation to loss, adaptation to chronic health conditions and adapting families.

\section{Assumptions}

Roy's Model of Adaptation evolved from the grand theory of the General Systems Model, which perceives the world as interconnected systems that influence each other (Whetsell, Gonzalez, \& Moreno-Fergusson, 2015). Early assumptions of the Roy Model of Adaptation were based on scientific and philosophical assumptions. Scientific assumptions were founded on Von Bertalanffy's (1968) General Systems Theory and Helson's (1964) Adaptation Theory. Subsequently, Roy incorporated Young’s (1986) concept of cosmic unity in which there are common patterns and integral relationships 
found in people and the earth. Early philosophic assumptions of Roy's Model of Adaptation included humanism, creativity, purposefulness, holism and interpersonal process.

Humanism is based on the concepts of "knowing and valuing" (Roy, 2009, p. 28). There exists the belief that humans behave in a purposeful manner, which affects awareness and understanding. Humanism also incorporates the philosophic assumption of human's relationship with the world and a God-figure. God is the common destiny of creation, and humans are responsible for sustaining and transforming the universe through the use of God given attributes such as awareness, enlightenment, and faith (Roy, 2009). In 1988, Roy coined the term veritivity which is based on the Latin word veritas meaning unity, purposefulness of humankind, creativity, value and meaningfulness of life (Roy, 2009).

Roy's world travel and global lecturing began in the 1980's. Enriched and inspired by world travel and a desire to have the model transcend and incorporate cultural diversity, additional cultural assumptions were incorporated in an effort to assist nurses from various ethnic groups understand the model and make it more relevant to their cultural practices (Frederickson, Acuna, Whetsell, \& Tallier, 2005).

\section{Concepts and Definitions}

The main feature of Roy's Model of Adaptation is to fulfil an individual's potential through the concept of adaptation. Individuals are described as adaptive systems; they have internal and external processes which function to maintain integrity of the individual. Processes are regulated through two subsystems - regulator and cognator. Regulator subsystems are comprised of physiological processes of the endocrine and 
exocrine systems. An example of this would be the chemical flood of epinephrine and blood flow to major organs in preparation for "fight or flight" response. The cognator subsystem responses refer to the emotional and cognitive processing of a "fight or flight" response (Roy, 2009). Roy describes four basic manifestations of subsystem response which are termed adaptive modes. The four modes of adaptation are physiological/physical, self-concept/group identity, role function, and interdependence.

Coping is also addressed by Roy's Model of Adaptation which includes the ability of the system's capacity to regulate and stabilize. Coping processes are defined as "innate or acquired ways of interacting with, that is, responding to and influencing the changing environment" (Roy, 2014, p. 41). The adaptation model speaks to the process of adapting to one's situation in a holistic manner, incorporating all the facets of our complex bio-psychosocial beings (Roy, 2009). Maladaptation occurs when an individual is unable to respond appropriately to internal or external stimulation.

\section{Concept Relationships}

Roy identified the major elements of her model as adaptation, person, environment, health, and the goal of nursing. Incorporating General Systems Theory, people are viewed as adaptive systems having input and output processes, which fluidly adapt to the environment in an effort to move towards health and well-being. Systems incorporate input or stimuli (either external or internal) which provokes a response; this is the contact point between the human system and the environment. Adaptation level to stimuli is represented by the status or condition of the person. 
Roy identifies three levels of adaptation: Integrated, compensatory, and compromised. A person's life process and response (output) to stimuli is representative of adequate or inadequate ability of the individual to adapt or reestablish adaptation. If the system's controls are inadequate, compromised adaptation will occur (Roy, 2009). Adaptive responses are focused on a person's environmental choices which can promote or hinder health. Our systems are wired towards survival of the species, and includes reproduction, growth and survival. Environmental choices such as smoking or drug abuse are examples of ineffective adaptation responses. Hyperacusis in the child with autism is an ineffective adaptation response to sound which impairs understanding, social relationships and learning.

Health is a concept upon which Roy has expanded over the years of model development. The current definition of health is described by Roy as "a state and a process of being and becoming an integrated and whole person” (Roy, 2009, p. 48). Holism refers to an underlying principle of the Roy model in which humans are holistic adaptive systems. There is unity in diversity and the whole is worth more than the sum of its parts (Roy, 2009). Roy expanded on Florence Nightingale's philosophy and commitment to those who suffer. A goal of the nursing process is "to alleviate environmental factors that contribute to illness and assist in the natural elements and process of healing oneself"' (Roy, 2009, p.4). According to Roy, nursing efforts should be focused on management strategies that enhance patients' well-being through positive interactions with their environment (Clarke, Barone, Hanna, \& Senesac, 2011; Whetsell, Gonzalez, \& Moreno-Fergusson, 2015). 


\section{Theory Applicability to Project Population and Setting}

For those individuals and families walking the lifetime path of ASD, there is an underlying inspirational hope and sense of unity manifested through family and community support, growing awareness and education towards ASD recognition, early diagnosis, early intervention and active research. Dr. Roy recognized the great resiliency of children and their families in response to a health crisis, and identified the significant role of the nurse in support and promotion of integrated and compensatory adaptation. Recognizing that nursing intervention does not necessarily lead to health restoration, Roy identified the role of the nurse in promotion of positive coping in chronic illness. Nursing requires careful and comprehensive assessment of behaviors and factors which affect adaptation. Interventions designed toward promotion of coping and adaptive abilities are beneficial while positively interacting with one's environment and spirituality (Roy, 2014).

The grief cycle is a natural human process which occurs when one experiences loss. Divorce and death of a loved one have been identified as the two most significant events initiating profound grief. Parents, particularly mothers of a child with a disability, describe a state of 'chronic sorrow' from the time of diagnosis or recognition that something is 'wrong' throughout the rest of their life span (Parrish, 2010; Thurgate \& Warner, 2005). Expected or unexpected life experiences can retrigger the grief process. Mothers of children with disabilities describe feelings of grief and loss continuing long beyond the time of the initial diagnosis. While joy and happiness are experienced, many parents describe a process of repeating the grieving process over and over. Parents 
commonly express feelings of shock at the time of diagnosis followed by a cycle of guilt, isolation, panic, anger, bargaining, final acceptance and hope (Boushey, 2001; Maloret \& Sumner, 2014). This cycle is often repeated when a new diagnosis or medical crisis occurs. The grieving process is considered to be a compensatory process of adaptation which includes four modes of adaptation: Loss of physical function, loss of sense of self, loss of role function, and loss of interpersonal relationships (Parrish, 2010; Roy, 2009). Roy's Model of Adaptation identifies the grieving process as a significant component of growth, which is not a pathologic process but one in which a higher level of transformation and personal integrity can occur (Roy, 2014).

\section{Theory Relevance to DNP Project}

The goal of this project was to explore effective ways for controlling the auditory environment of the child with ASD and hyperacusis, and to present a method to manipulate auditory input in a safe and simple way. Therapeutic Listening Communication (TLC), utilized existing noise cancelling technology, in conjunction with individualized user control on the auditory input received. This method allowed more complete tailoring of what the client experienced in hearing, and thus better focused on the targeted outcomes of a session, whether the goal is a learning interaction with one or more teachers, parent communication with their child, or just respite from a noisy world.

Roy's Model of Adaptation blends seamlessly with the DNP project of modifying the sensory perception of the child toward compensatory and integrated adaption while incorporating the other major elements of person, environment, and health. The goal of the nursing project was based on Roy's philosophy of focusing on a human's interaction with his or her environment to enhance well-being (Whetsell et al., 2015). The nursing 
goal is not curative, but rather an adaptation of stimulus which triggers a negative human response into a more tolerable stimulus, affording children with ASD and hyperacusis the ability to better cope with the environment. A positive benefit of integrated adaptation in the presence of hyperacusis would be an improved learning and social environment for the child and his or her family. Early intervention and improved methods of communication and management of hyperacusis based on systems theory benefits the system by integrating the bio-psychosocial and spiritual components of the individual, their family unit and society (Roy, 2014; Stiegler \& Davis, 2010). 


\section{CHAPTER 2: REVIEW OF THE LITERATURE}

\section{Autism Spectrum Disorder and Hyperacusis}

Using a quantitative retrospective design, Lucker (2013) examined 1,000 medical records of children referred to the clinic for the primary complaint of auditory hyperacusis. Medical records were included if hearing was determined to be normal and there was a medical diagnosis of ASD with no other deficits. The sample size included 35 males and 15 females who met the criteria. Additionally, [( $n=200),(138$ males and 62 females)] with auditory hypersensitivity but not having ASD were selected. Tolerance levels to sound were tested up to $110 \mathrm{~dB}$ as measured by the Loudness Discomfort Level (LDL). Chi-square analysis compared children with ASD and those without ASD by age, group and gender. Findings revealed loudness tolerance was not related to age or gender. A smaller number of children than hypothesized were unable to tolerate loud sounds (90$110 \mathrm{~dB}$ ), possibly indicating auditory hypersensitivity may be related to a conditioned response to sound perceived as aversive versus a disorder of the audiological system. A strength of this study was the inclusion of children; the majority of available studies have focused on teenage and older populations.

Steiglar and Davis' (2010) qualitative review of literature focused on sensitivity to sound in individuals with and without ASD. Auditory hypersensitivity is commonly associated with terms such as phonophobia, which is an abnormally strong response of the autonomic and limbic system, and misophonia, which is a learned emotional response to sound (Stiegler \& Davis, 2010). According to empirical data and personal accounts, aversive behavioral responses frequently occur in children with ASD to normally tolerated sounds such as a toilet flushing or water draining from the bathtub. The child 
can then negatively transfer the sound to the verbalization of the word 'bath' or 'water'.

A case example of the use of a Social Story was described, in which a child with an aversion to a haircut is gradually and repeatedly introduced in the form of a story to desensitize the child. This therapy was found helpful in desensitizing the child, with a decrease in adverse behaviors measured at the child's next haircut appointment. A strength of this study was an extensive review of literature focusing on therapeutic listening communication therapy. A weakness was just one case study of using the social story technique that provided limited information regarding the benefits of this technique.

Impaired tolerance to sound has been identified in various syndromes with prevalence studies ranging from $6 \%-42 \%$ and increasing to $90 \%$ in individuals afflicted with Williams Syndrome (Levitin, Cole, Lincoln, \& Bellugi, 2005). Salvi, Wang and Ding, (2000) discussed the possible role of auditory plasticity or increased gain within the central auditory pathway. Opponents of this theory argue that while individuals with hyperacusis have normal audiometric levels, commonly there is a shift in LDL of 4050dB. Human auditory deprivation studies have only shown a decrease in LDL by $7 \mathrm{~dB}$ in relationship to their normal LDL levels (Munro \& Blount, 2009). While the relationship between the biological mechanisms leading to hyperacusis is unclear, growing evidence is finding a correlation between the loss of gamma-aminobutyric acidmediated inhibition at several levels in the auditory pathway (Aazh et al., 2014; Salvi et al., 2000). 


\section{Impact of Hyperacusis and Learning}

In 2002, the American National Standards Institute approved a standardization for minimum guidelines establishing classroom acoustics in order to facilitate the learning process, ANSI S12-60-2002 (American National Standards Institute, 2002). These guidelines include classroom maximum levels of background noise and reverberations with the goal of creating classroom environments conducive to learning. However, studies have shown that these requirements are rarely met (Johnston, John, Kreisman, Hall, \& Crandell, 2009). Crandell, Smaldino and Flexer, (2005), found 32 typical classrooms with measurements of sound levels far exceeding recommended standards. In addition to the average classroom noise, those with hyperacusis may have diminished academic performance and difficulties with adverse behaviors, attention and concentration abilities (Johnston et al., 2009). Left untreated, hyperacusis not only leaves the learner frustrated, but compounds underlying issues with anxiety, loss of self-esteem, isolation and depression (Aazh et al., 2011; Gomes et al. 2004; Groen et al., 2009).

\section{Hyperacusis Treatment Modalities}

Prior to any treatment modality, it is essential to determine that no hearing loss or medical condition exists which could potentially exacerbate or confound treatment. Since hyperacusis and tinnitus frequently coexist, treatment modalities are generally geared similarly. One example is the Hyperacusis Activity Treatment, in which individuals are counseled on four components; thoughts and emotions, hearing and communication, sleep, and lastly concentration (Tyler et al., 2006). The goal of treatment is to develop an ability to recognize sound and the individual's response to sound (Pienkowski et al., 2014). Sound-therapy treatment includes several modalities, such as 
low-level broadband noise generation, gradually increasing exposure to high noise levels, noise masking with sound or music and cognitive behavior therapy. Each of these treatments will be discussed and reviewed sequentially.

\section{Cognitive Behavior Therapy}

Juris, Anderson, Larsen and Ekselius's (2014) randomized controlled trial, compared the effects of cognitive behavior therapy (CBT) of 60 individuals with hyperacusis with a waiting list control group. Their study was based on previous findings that CBT has been beneficial in reducing avoidance behavior in individuals with chronic pain and tinnitus. Potential benefit of CBT between the two groups was measured by use of the Loudness Discomfort Level (LDL), the Hyperacusis Questionnaire (HQ), the Hospital Anxiety and Depression Scale (HADS), the Quality of Life Inventory (QLI) and an adapted version of the Tampa Scale of Kinesiophobia. ANCOVA analysis demonstrated a significant between-group effect on the LDL test for both ears $(p<0.001)$. ANCOVA showed significant group effects for the depression scale, but not the anxiety scale. A significant treatment effect $(F(1,55)=4.3, p<0.01)$ was shown on the QLI and the Tampa Scale of Kinesiophobia $(F(1,55)=47.1, p<0.001)$. Results indicated CBT may be helpful for treatment of hyperacusis but additional research is necessary. Juris et al., (2014), provided an extensive review of literature and reliable testing instruments. On the other hand, the authors point out that all the participants had been referred to an audiology clinic and were perhaps more affected by hyperacusis than the general population, thus potentially skewing the findings.

The purpose of Gomes, Rotta, Pedroso, Sleifer, and Danesi, (2004) study was to verify whether observed clinical behavioral response to auditory sensitivity, as measured 
by interviews with parents/caregivers and therapists/teachers of children and teenagers with ASD correlate to audiological findings, as measured by acoustic stapedius reflex and observed responses to intense acoustic stimulus. The population included 46 children and teenagers who regularly received care at a pediatric clinic $(n=46)$. Results demonstrated 11 subjects $(23.9 \%)$ were clinically diagnosed as hypersensitive to sound and 2 demonstrated discomfort. Ipsilateral acoustic stapedius reflexes between the groups showed no statistical difference. The researchers concluded that behavioral manifestations associated with auditory hypersensitivity are not related to a disturbance in the audiology pathway, but rather an impairment of upper processing systems such as the limbic and autonomic nervous system. A strength of this study is utilization of measurement tools with demonstrated validity. A weakness is that the study is now over 10 years old and did not specify the measurement tool used for the interview process to determine auditory hypersensitivity.

\section{Sound Therapies}

Porges et al., (2014) introduced the listening project protocol (LPP) in which children with ASD and hyperacusis were introduced to five daily sessions each lasting 45 minutes, of computer altered vocal music which was designed to exaggerate the sound of human voice, with the hypothesis that filtered music would decrease auditory hypersensitivity by regulating the muscles of the middle ear. The experimental design consisted of two sequential randomized controlled trials with parallel control groups. Trial one consisted of filtered music with headphones only, while Trial two contrasted filtered music with unfiltered music with headphones. In both trials (Trial one, $n=73$ and Trial two, $n=82$ ), analysis of variance was analyzed for each of the 10 behavioral 
questionnaire dimensions the authors developed. Significant improvements were shown in the filtered music group in hearing sensitivity $(F(1,29)=6.46, p=.0017)$, spontaneous speech $(F(1,49)=5.61, p=0.022)$, listening $(F(1,52)=8.25, p=0.006)$ and behavioral organization $(F(1,34)=5.39, p=0.027)$. The one week post-intervention analysis of variance concurred with the previous results. A strength of the study was that the population studied was a significant sample size of children with ASD, many of whom also had auditory hyperacusis. The study was conducted in a controlled research setting. A limitation of the study identified by the authors was the subject participants were concurrently receiving other treatment interventions such as behavioral therapy which might have altered the study's findings.

The Tomatitis Method is an alternative treatment which incorporates prepared tracks of Mozart's music and Gregorian chants which have been designed to modulate the acoustical signal. The individual wears headphones equipped with a device that allows sound to be received through both bone and air conduction (Corbett, Shickman, \& Ferrer, 2008). A small study ( $\mathrm{n}=11$ ) was conducted at the UC Davis M.I.N.D. Institute to determine if the Tomatis Method had an effect on language skills in children. While this randomized, double-blind, placebo-controlled, crossover design did indicate overall percent change of general improvement in language Group 1 (Placebo/Treatment) for treatment was $17.41 \%$ and placebo was $24.84 \%$. Group 2 (Treatment/Placebo) demonstrated $-3.98 \%$ change for treatment and $14.15 \%$ change for placebo (Corbett et al., 2008). The authors concluded there was no significant difference on language measures resulting from the intervention, but noted this was the only known experimental study for this method of alternative treatment in children with ASD. A response to this study was 
published in the same journal in 2008 disputing the conclusions based on research errors (Gerritsen, 2008). While errors were noted in the research methodology, Gerritsen (2008), pointed out favorable improvement in reduction of hyperactivity, atypical behavior and improvement of attention and overall communication. However, due to the small sample size, this study was underpowered and could not support any conclusions. While the Tomatis Method is still being advocated and utilized by many Occupational Therapists, there is a dearth of evidenced-based research supporting this treatment.

\section{Noise Generation Therapy}

While noises can have detrimental effects on behavior and performance, sound therapy or noise generation therapy has benefited those with hyperacusis and tinnitus (Norena \& Chery-Crose, 2007; Norena, 2011). Wideband noise generators (WNG) are commonly used in management of hyperacusis (Aazh et al., 2014), and are considered safe as long as the individual can adjust the noise generated to a comfortable level (Aazh, Moore, \& Prasher, 2011).

White and pink noise are two common examples of wideband generated noise. White noise is defined as a signal made by uncorrelated, random frequencies; it is a sound that contains every frequency within the human range of hearing, generally $20 \mathrm{~Hz}$ to $20,000 \mathrm{kHz}$, with equal energy across the spectrum (Loh, Yegnanarayanan, Ram, \& Juodawlkis, 2013). The term white noise is analogous with white light, which occurs when all light frequencies are summed into a single beam (Cook, Bradley-Johnson, \& Johnson, 2014). Human hearing senses frequencies on a logarithmic scale (octaves) as opposed to a linear scale. White noise is perceived by the ear as having more high frequency than low, although the sound energy is equal in each octave; this phenomenon 
occurs because each higher octave has twice as many frequencies as the one preceding it (Groen et al., 2009; Helps, Bamford; Sonuga-Barke, \& Soderlund, 2014).

White noise has been found to be very effective in noise masking thus having direct applications for treatment of tinnitus (Rosenhouse, 2014). White noise has also been found to improve hearing performance by altering the 'signal to noise' ratio through stochastic resonance (SR) as noted by Helps, Bamford, Sonuga-Barke, \& Soderlund, (2014). SR is a physical phenomenon whereby a signal, in this case audible sound, can be boosted or enhanced by mixing white noise (WN) with the signal. Frequencies within the white noise bandwidth can resonate with the original signal's frequencies and thus amplify the original signal while not amplifying the rest of the white noise frequencies (Low et al., 2013). Helps et al., (2014), researched whether particular WN levels were of benefit in improving cognitive ability in children (aged 8-10 years) with varied teacherrated attention abilities; super-attentive $(n=25)$; normal-attentive $(n=29)$, and subattentive $(n=36)$. The children performed two non-executive function tasks and two executive function tasks under three WN levels; low, moderate and high. Non-WN was used as a control. Results indicted adding WN decreased the performance for superattentive children, but improved performance in sub-attentive children. Normal-attentive children's scores did not demonstrate a measurable difference. Additionally, increasing WN from moderate to high levels did not affect performance. Findings suggest that a benefit from WN is auditory masking. Researchers suggested that if the subjects had been able to select their own WN level that was optimal for them, the WN may have demonstrated better benefits. This recent study is one of a handful investigating the effects of WN on attention and learning. The authors recommended further studies to 
investigate WN as a potential non-pharmacological treatment for inattention (Helps et al., 2014).

Pink noise is defined as acoustical energy distributed uniformly by octave through the range of hearing (Loh et al., 2013). Most humans perceive pink noise as having a more uniform spread of sound, as opposed to white noise, and the same apparent loudness at all frequencies. Pink noise is generated from white noise. Whereas white noise contains equal energy across the entire audio spectrum, pink noise is equal energy within each octave; it is "filtered" such that energy is decreased in each succeeding octave, corresponding to a 50\% energy reduction $(3 \mathrm{~dB})$ from the preceding octave (Loh et al., 2013; Pienkowski et al., 2014).

Pink noise has a greater relative proportion of low frequency energy than white noise and sounds less 'hissy'. Since human hearing processes frequencies logarithmically, pink noise is perceived as having a prominent peak around $3 \mathrm{kHz}$, which is sometimes more rhythmic and soothing, therefore having applications in soothing infants and inducing calmness (Groen et al., 2009). In healthcare and classroom applications, pink noise has been used to treat hyperacusis or to mask tinnitus (Aazh et al., 2014; Hyche \& Maertz, 2014; Pienkowski et al., 2014).

Current studies have indicated longer term noise generator therapy may have greater benefits than short term therapy as described as more than one or two months (Norena \& Chery-Crose, 2007; Pienkowski et al., 2014). Further evidenced-based controlled studies with a large amount of subjects is recommended to substantiate findings. 


\section{Noise Cancelling Headphones}

While noise cancelling headphones are helpful in reduction of environmental noise, counterproductive side effects such as increased auditory gain, exacerbation of hyperacusis when ear protection is not being utilized, combined with fear of environmental situations which typically provoke stress have been observed (Aazh, Moore, \& Prasher, 2011; Wang \& Ren, 2012;).

\section{FM Wireless Systems}

Personal FM wireless systems have been used in special education classrooms for many years to assist with processing of auditory information for children with ASD, with positive results for improved speech reception and attention/on-task behaviors (Alcantara, Weisblatt, Moore, \& Bolten, 2004; Corbett \& Constantine, 2006; Tomchek \& Dunn, 2007). Personal FM systems utilize a wireless microphone, which transmits the speaker's voice to the listener by radio waves, therefore bypassing other environmental noises.

Currently, few other alternative therapies for hyperacusis are available.

Medication trials have proven unsuccessful (Pienkowski et al., 2014; Tyler, 2012). Electrical stimulation of the cochlea has demonstrated a reduction in tinnitus which often co-exists with hyperacusis (Engineer et al., 2011; Tyler et al., 2008).

\section{Review of Literature Gaps}

Thus far, numerous studies describing the association of ASD and auditory hypersensitivity exist, however sparse research in therapy modalities such as therapeutic listening communication are available. The benefits of white noise and pink noise have been clearly documented in the treatment of hyperacusis, tinnitus, and as a nonpharmaceutical sleep aid. This project addressed the gaps noted in the literature by 
identifying the association between auditory hypersensitivity and application of Therapeutic Listening Communication. The project was an application of existing noise cancelling technology, and provided individualized user control of white and/or pink noise levels, along with a wireless microphone receiver. While these topics have been researched individually, this researcher's task was to compile research in a manner which directed and promoted the adaptation of current technology in a new therapeutic approach. 


\section{CHAPTER 3: METHODOLOGY}

\section{Institution Review Board Approval}

This research project was approved by both the California State University, Fresno School of Nursing Institutional Review Board, and a full review by the California State University, Fresno Committee for the Protection of Human Subjects.

\section{Subjects}

This pilot study sampled four children diagnosed with ASD and hyperacusis. The rationale for this small sample size was the introduction of new technology (TLC) which needed to be piloted for application and effectiveness. Participants were recruited and selected by the Director of Special Education in conjunction with the Special Education Classroom lead teacher from two small classroom sites. Three Special Education Classrooms were located at two different campuses within the Pleasant Ridge School District in Western Nevada County, and all classroom site programs are administered through the School District. Application of TLC was utilized at the same time for two students (M-1 and F-1) in a $5^{\text {th }}$ grade classroom during math, and two Kindergarten student (M-2 and F-2) in separate classrooms while the students worked either with the Special Education Classroom teacher or directly with the student's assigned Special Education Teaching Assistant. At all times a Special Education Classroom teacher was present in the classroom. Inclusion/exclusion criteria was as follows: Children, ages 6-13 (K-8 ${ }^{\text {th }}$ grade) who: 1$)$ have a confirmed diagnosis of Autism Spectrum Disorder (ASD) as described by the DSM V Criteria (American Psychiatric Association [APA], 2015), 2) are under the active care of a medical doctor, 3) are free of otitis media, serous otitis media or cerumen blockage as observed by audiological exam 
and tympanogram (performed by myself , a California Credentialed School Nurse, Certified School Audiometrist and Certified Pediatric Nurse Practitioner), 4) demonstrate hearing levels better than $40 \mathrm{~dB}$ on the best ear as demonstrated by standardized audiometric testing administered as stated above, and 5) demonstrate no evidence of uncorrectable visual impairment or other physically disabling conditions that would interfere with the ability to participate (other than that normally found in individuals with ASD).

Parent information sessions and written materials provided to the families was written as close to a $6^{\text {th }}$ grade reading level as possible. Additionally, the researcher's contact information was provided in case families had questions. Participants in the study were given the opportunity to choose to participate in each session by being verbally asked 'If you want to stop [participating in instruction], tell me 'Stop please'. Do you understand?" Non-verbal/behavioral cues like fidgeting, increased anxiety, off task behaviors or the sign for "stop" were taken as signs that the child may not want to participate. Children demonstrating those types of behaviors were asked if they wished to continue (see above). Additionally, classroom instructors and parents or a legally authorized representative could stop study participation at any time.

\section{Methods}

A single-subject multiple-baseline mixed methods design was used to determine the effectiveness of Therapeutic Listening Communication (TLC) in the Special Education Classroom during normal instructional activities. Research requirements included that children must be able to sit for a period of 10-15 minutes independently and also work independently within the structure of the special education classroom. The 
dependent variable (DV) consisted of the participating children who could consistently answer yes/no questions and one step directions at a minimum. The independent variable (IV) was the application of TLC while the children were engaged in developmentally appropriate tasks normally done in the Special Education Classroom setting.

Three phases of single-subject multiple-baseline were implemented to monitor the degree of change in chosen behaviors as a result of intervention. These phases were 1) baseline, 2) instruction/application of TLC and 3) maintenance. During all three phases of research, the participants were in their normal classroom environment. The TLC device was worn by the child, with the instructor utilizing the FM wireless microphone, but no implementation of white or pink noise. The purpose of this phase was to acclimate the user to the TLC device, thus ensuring that behavioral change could be attributed to the instruction/application of TLC and not to other external factors such as the novelty of the device. Following four sessions of the baseline phase, the instruction/treatment phase began. This second phase consisted of application of TLC for periods of 15-30 minutes each and was administered during four sessions of normal classroom instruction. Again the instructor utilized the FM wireless microphone and the child utilized the TLC device, but white and/or pink noise was now introduced, and the child could adjust their preferred noise to a comfortable level. This level was then preset for the child in each subsequent session, so as to minimize any distractions that may be caused by the device's novelty. The third phase consisted of four sessions of maintenance, in which the device 
was utilized as in phase one and any changes in behavior were closely monitored by the researcher. The following table documents the research sessions conducted on each

\begin{tabular}{|c|c|c|c|c|c|c|c|c|c|c|c|c|}
\hline \multicolumn{13}{|l|}{ Student: F1 } \\
\hline Session \# & 1 & 2 & 3 & 4 & 5 & 6 & 7 & 8 & 9 & 10 & 11 & 12 \\
\hline Session Date (2015): & $11 / 2$ & $11 / 4$ & $11 / 9$ & $11 / 10$ & $11 / 16$ & $11 / 18$ & $11 / 23$ & $11 / 30$ & $12 / 2$ & $12 / 3$ & $12 / 7$ & $12 / 11$ \\
\hline Application W/O noise: & $x$ & $x$ & $x$ & $x$ & & & & & $x$ & $x$ & $x$ & $x$ \\
\hline Application with noise: & & & & & $x$ & $x$ & $x$ & $x$ & & & & \\
\hline Minutes Applied: & 30 & 30 & 30 & 30 & 25 & 40 & 35 & 40 & 35 & 45 & 45 & 50 \\
\hline \multicolumn{13}{|l|}{ Student: $\mathbf{M 1}$} \\
\hline Session \# & 1 & 2 & 3 & 4 & 5 & 6 & 7 & 8 & 9 & 10 & 11 & 12 \\
\hline Session Date (2015): & $11 / 2$ & $11 / 4$ & $11 / 9$ & $11 / 10$ & $11 / 16$ & $11 / 18$ & $11 / 23$ & $11 / 30$ & $12 / 2$ & $12 / 3$ & $12 / 8$ & $12 / 9$ \\
\hline Application W/O noise: & $x$ & $x$ & $x$ & $x$ & & & & & $x$ & $x$ & $x$ & $x$ \\
\hline Application with noise: & & & & & $x$ & $x$ & $x$ & $x$ & & & & \\
\hline Minutes Applied: & 30 & 30 & 30 & 30 & 25 & 40 & 35 & 40 & 35 & 45 & 45 & 50 \\
\hline \multicolumn{13}{|l|}{ Student: F2 } \\
\hline Session \# & 1 & 2 & 3 & 4 & 5 & 6 & 7 & 8 & 9 & 10 & 11 & 12 \\
\hline Session Date (2015): & $11 / 2$ & $11 / 4$ & $11 / 9$ & $11 / 10$ & $11 / 16$ & $11 / 18$ & $11 / 24$ & $11 / 30$ & $12 / 2$ & $12 / 3$ & $12 / 7$ & $12 / 14$ \\
\hline Application W/O noise: & $x$ & $x$ & $x$ & $x$ & & & & & $x$ & $x$ & $x$ & $x$ \\
\hline Application with noise: & & & & & $x$ & $x$ & $x$ & $x$ & & & & \\
\hline Minutes Applied: & 30 & 25 & 20 & 25 & 25 & 25 & 15 & 20 & 20 & 15 & 20 & 15 \\
\hline \multicolumn{13}{|l|}{ Student: $\mathbf{M} 2$} \\
\hline Session \# & 1 & 2 & 3 & 4 & 5 & 6 & 7 & 8 & 9 & 10 & 11 & 12 \\
\hline Session Date (2015): & $11 / 2$ & $11 / 4$ & $11 / 9$ & $11 / 10$ & $11 / 16$ & $11 / 18$ & $11 / 23$ & $12 / 2$ & $12 / 3$ & $12 / 7$ & $12 / 8$ & $12 / 9$ \\
\hline Application W/O noise: & $x$ & $x$ & $x$ & $x$ & & & & & $x$ & $x$ & $x$ & $x$ \\
\hline Application with noise: & & & & & $x$ & $x$ & $x$ & $x$ & & & & \\
\hline Minutes Applied: & 30 & 30 & 30 & 25 & 25 & 20 & 25 & 20 & 15 & 20 & 20 & 20 \\
\hline
\end{tabular}

subject during the study. 


\section{Dunn's Sensory Processing Framework}

Dunn's Sensory Processing Framework provides a visualization to conceptually describe interactions between neurological thresholds and self-regulatory behavioral responses (see Figure 3.1). According to Dunn (2014), children demonstrate behaviors which can be characterized into four sensory processing patterns. Please refer to Appendix 1 for a definition of terms used in Dunn's (2014) sensory processing patterning scores.

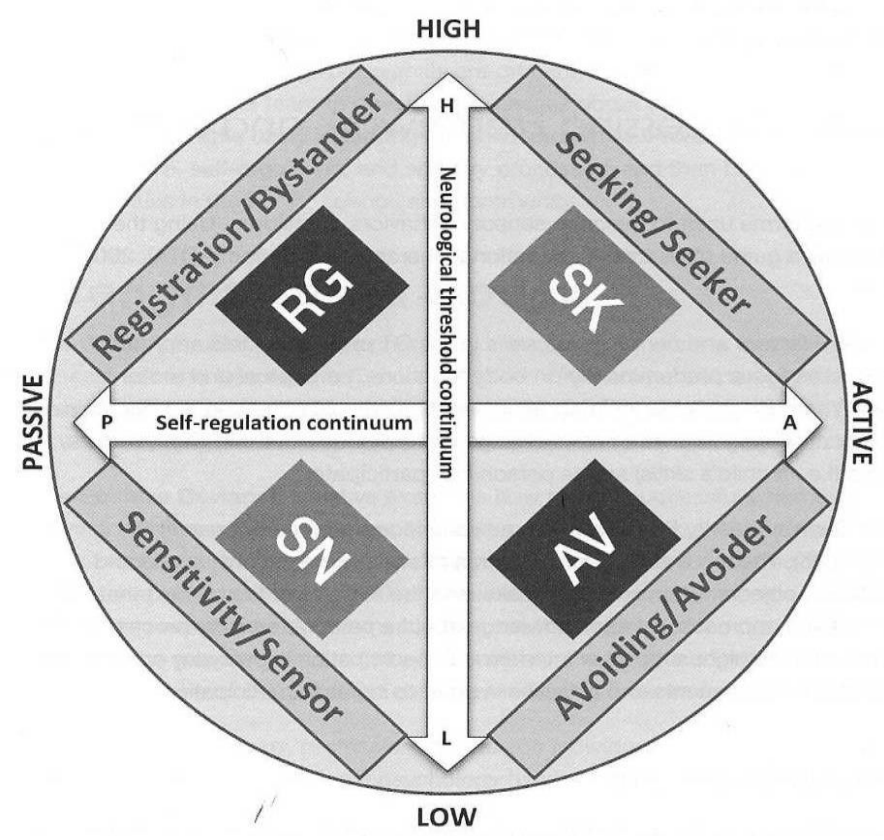

Figure 3.1: Dunn's Sensory Processing Framework

Source: From Dunn, W. (2014). Sensory profile 2: Strength-based approach to assessment and planning, p. 11. Upper Saddle River, NJ: Pearson Education. Reprinted by permission of Pearson Education Inc.

These processing patterns are: Registration/Bystander, Seeking/Seeker, Avoiding/Avoider and Sensitivity/Sensor. The neurological threshold continuum can be found in a range from low to high, while the self-regulation continuum can be very passive to extremely active. Registration/Bystander is described as a high neurological 
threshold with the characteristic of passive self-regulation. These individuals often miss sensory cues that others normally are attentive to, such as a piece of clothing being twisted or someone calling their name. Seeking/Seeker is also a high neurological threshold but self-regulation strategies are active. These children are actively seeking sensory input such as tapping items, chewing pencils or touching items.

Sensitivity/Seekers are low neurological thresholds with passive strategies of selfregulation. Sensitivity/Seekers, as the name implies, are the ones who tune in to sounds, visual cues, and patterns that others may not observe. Self-regulatory strategies may include covering their ears, picky eating behaviors, or avoiding loud and bright activities. The last quadrant, Avoiding/Avoiders, have low neurological thresholds, but have active self-regulatory patterns. These children will go to great lengths to maintain order and routines with the purpose of avoiding change and unanticipated stimulation.

\section{Interpretation of Sensory Profile $2^{\mathrm{TM}}$ Scoring Results}

This study utilizes the Sensory Profile $2^{\text {TM }}$ (SP 2), a nationally validated, established and accepted tool for professionals to document children's sensory processing patterns. When combined with participant information, this contributes to identifying the effect of sensory processing on functional participation in the context of a child's home, school and community (Dunn, 2014). This tool provides information into determining how a child's sensory processing may or may not be interfering with the school setting and in everyday life. The primary purpose of the SP $2^{\mathrm{TM}}$ and the reason it was appropriate for this study, is to provide a measurement of the child's current performance, overall impressions over a span of time and in response to an intervention (Dunn, 2014). 
Data collection consisted of baseline and post application measurements of attentiveness, behavioral response and facilitated learning, as measured by the SP $2^{\mathrm{TM}}$, which contains two questionnaires, one for the parent/caregiver and one for the classroom instructor. The SP $2^{\mathrm{TM}}$ assessment contains age-appropriate questionnaires; this pilot study utilized the questionnaire series for children 3.0-14.11 years of age. The caregiver questionnaire is composed of 86 questions, and the instructor's questionnaire is composed of 44 questions. The questions in both questionnaires solicit a measurement of the child's sensory processing patterns, sensory system and behaviors; the instructor's has the additional measurement of school factors. The caregiver and teacher are asked to report the frequency with which these behaviors occur; 'almost always', 'frequently', 'half the time', 'occasionally', or 'almost never'. A 'does not apply' category is also provided should the scorer feel the question is not relevant to the child (Dunn, 2014). Raw scores are tallied and transferred to a separate sheet, which then guides the user through processing the resultant scores into the SP $2^{\text {TM }}$ statistical analysis (Dunn, 2014). Table 3.2 shows the scoring distribution of the caregiver scores and Table 3.3 provides an example of the teacher's scores. 
Table 3.2 - SP2 ${ }^{\mathrm{TM}}$ Caregiver Questionnaire Scoring Sheet.

The Normal Curve and Sensory Profile 2

Classification System

Scores one standard deviation or more from the mean are expressed as More Than Others or Less Than

Others, respectively. Scores two standard deviations or

more from the mean are expressed as Much More Than

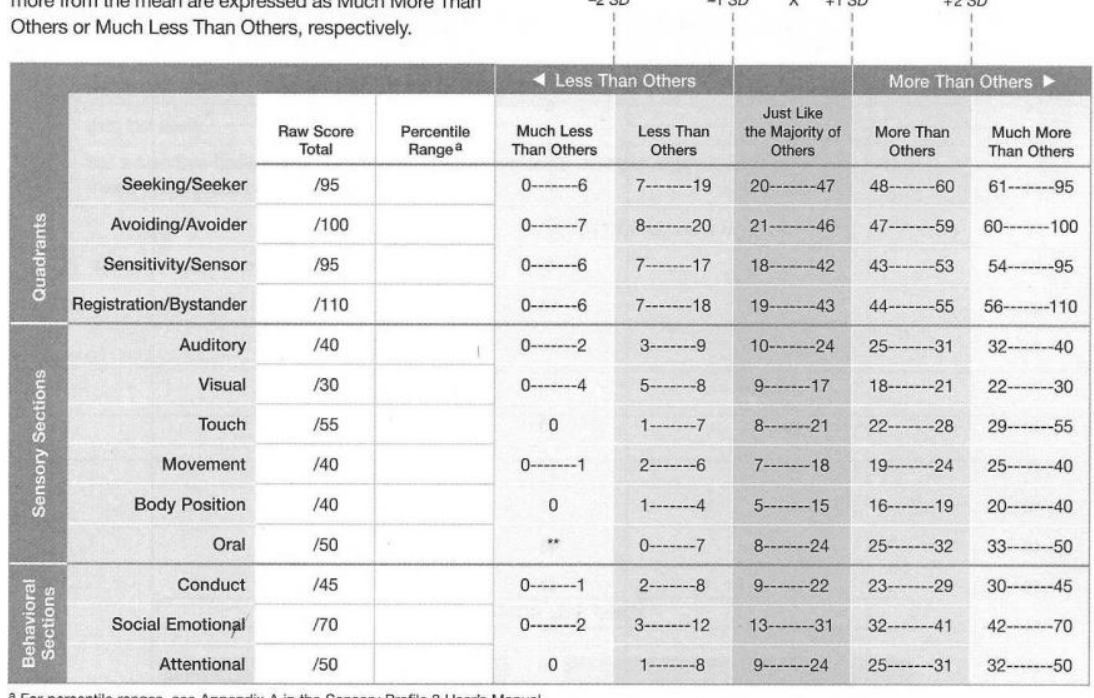

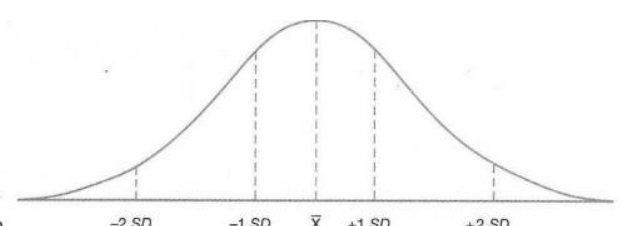

a For nercentile ranoes. see Anoendix $A$ in the Sensonv Profile 2 User's Manual.

Table 3.3 - SP2 ${ }^{\mathrm{TM}}$ Teacher Questionnaire Scoring Sheet.

The Normal Curve and Sensory Profile 2 Classification System

Scores one standard deviation or more from the mean are expressed as More Than Others or Less Than

Others, respectively. Scores two standard deviations

or more from the mean are expressed as Much More Than Others or Much Less Than Others, respectively.

\begin{tabular}{|c|c|c|c|c|c|c|c|c|}
\hline \multirow{6}{*}{$\begin{array}{l}\text { हैँ } \\
\frac{\mathrm{c}}{\mathrm{d}} \\
\text { वें }\end{array}$} & & & & \multicolumn{3}{|c|}{4 Less Than Others } & \multicolumn{2}{|c|}{ More Than Others - } \\
\hline & & $\begin{array}{c}\text { Raw Score } \\
\text { Total }\end{array}$ & $\begin{array}{l}\text { Percentile } \\
\text { Range }^{\mathrm{a}}\end{array}$ & $\begin{array}{l}\text { Much Less } \\
\text { Than Others }\end{array}$ & $\begin{array}{l}\text { Less Than } \\
\text { Others }\end{array}$ & $\begin{array}{l}\text { Just Like } \\
\text { the Majority of } \\
\text { Others }\end{array}$ & $\begin{array}{l}\text { More Than } \\
\text { Others }\end{array}$ & $\begin{array}{l}\text { Much More } \\
\text { Than Others }\end{array}$ \\
\hline & Seeking/Seeker & 140 & & 0 & $1 \ldots-6$ & $7-19$ & $20 \cdots-25$ & $26--40$ \\
\hline & Avoiding/Avoider & 160 & & $0-\cdots-1$ & $2-7$ & $8-\cdots-21$ & $22 \ldots-27$ & $28----60$ \\
\hline & Sensitivity/Sensor & $/ 55$ & & $0-\cdots-2$ & $3--9$ & $10 \cdots-23$ & $24-30$ & $31 \ldots-55$ \\
\hline & Registration/Bystander & $/ 65$ & & 0 & $1-9$ & $10---28$ & $29---37$ & $38---65$ \\
\hline & Auditory & $/ 35$ & & $0 \ldots-1$ & $2-\ldots-5$ & $6 \cdots-15$ & $16 \ldots \ldots-19$ & $20 \cdots-35$ \\
\hline$=$ & Visual & $/ 35$ & & * & $0 \cdots-5$ & $6---17$ & $18-\ldots-23$ & $24--35$ \\
\hline $6=$ & Touch & 140 & & 0 & $1--4$ & $5---15$ & $16--20$ & $21-40$ \\
\hline & Movement & 140 & & 0 & $1+\cdots-5$ & $6-\cdots-17$ & $18-\cdots-23$ & $24 \cdots-40$ \\
\hline ๓ & Behavioral & $/ 55$ & & $0-\cdots$ & $2--8$ & $9-\cdots-22$ & $23--29$ & $30-55$ \\
\hline$n_{2}^{2}-1-1-1$ & School Factor 1 & $/ 65$ & & 0 & $1-\ldots$ & $10-\ldots-28$ & $29 \ldots-37$ & $38-65$ \\
\hline & School Factor 2 & $/ 50$ & & $0 \ldots-\ldots$ & $3-\ldots 9$ & $10-\ldots-24$ & $25-\ldots-30$ & $31-\cdots-\ldots$ \\
\hline
\end{tabular}

Source: From Dunn, W. (2014). Child Sensory Profile 2:

Caregiver \& Teacher Questionnaire Scoring Sheet: 3.0 to 14.11 years. Bloomington, MN: PsychCorp/Pearson Clinical Assessment Education. Reprinted by permission of Pearson Education Inc. 
As described, Dunn's Sensory Processing Framework is the basis of SP $2^{\mathrm{TM}}$. Questions feed the raw score totals in each of the four quadrants. The SP $2^{\mathrm{TM}}$ scoring is further broken down into two subsections; sensory system scores (sensory sections) and behaviors associated with sensory processing scores (behavioral sections). Sensory system scores contains items related to general processing, auditory, visual, somatosensory (touch), vestibular (movement), proprioceptive (body position) and sensory processing which provides an overall indication of the sensory system response for quick screening and research information. The behaviors associated with sensory processing scores or behavioral sections relate to behaviors associated as having been identified as commonly associated with sensory processing, and provide additional information of how a child processes sensory information. The behavioral response section is broken into three parts: Conduct, social emotional responses, and attentional responses related with sensory processing. Four separate school factor scores are deduced on the school companion SP $2^{\mathrm{TM}}$, which incorporates the classroom teacher's perception of the students in the areas of a student's need for external supports to participate in learning, a student's awareness and attention during learning and lastly, the student's tolerance within the learning environment.

Scoring of the SP $2^{\text {TM }}$ is reflected on a normal distribution curve (See Table $3.2 \&$ 3.3). Each response is compared collectively to peer responses with the recognition that human sensory processing patterns occur along a continuum, similar to other human responses. Responses are recorded as 'much less than others' (-2 SD), 'less than others' (-1 SD), 'just like the majority of others' ( $\bar{x})$, 'more than others' (+1 SD), and lastly 'much more than others' (+2SD). The terms 'more than others' and 'less than others' is 
a strength-based characteristic in relationship to what is typically known about routine interests, routines, activities and settings (Dunn, 2014).

Sensory Profile $2^{\mathrm{TM}}$ questionnaires were completed by the participating parent/caregiver and teacher before testing began and again immediately after the testing period completed. The first questionnaire established a baseline of sensory processing for each student in the home and school environments. The second questionnaire was then used to measure any changes in the child's sensory processing after application of TLC. Instructional sessions were intermittently video recorded to permit fidelity checks. It was estimated that fidelity data was gathered on 25 percent of sessions. Observations were made to determine quality of child responses to the three phases of research as described above. Data collection began a few months after the start of the school year in order to allow students, parents and classroom instructors a period of adjustment to the new school year. Data collection occurred over a period of six weeks, excluding school breaks and holidays.

\section{Potential Benefits/Risks}

There are benefits to science, society, and to individuals with ASD and hyperacusis. It is anticipated that research findings will assist in tailoring what the student experiences in hearing, and may better focus on the targeted outcomes of a session, whether it is a learning interaction with one or more teachers, parent communication with their child, or respite from a noisy world. While this research may show trending and not be statistically significant, it is hoped that future research application could develop from this initial pilot study. 
A potential risk of the research could have been classroom disruption from research being conducted in a classroom setting. Classroom instructors could have potentially viewed the study as an added burden to their already taxed schedules. Another potential risk could have been an individual's response to TLC application, causing an increase in off-task behaviors such as agitation or loud vocalization.

\section{Precautions Taken to Minimize Risk}

Classroom instructors were fully informed of the research, voluntarily signed written consent and could choose to cease participation in the study at any time. This researcher and a research assistant were present at all times during the study periods and responsible for all aspects of data monitoring and collection. Prior to conducting research, a parent information meeting was held and the researcher's contact information was distributed in order for parents to be able to contact the researcher as needed. Parental consent and child assent was voluntary and they could also elect to discontinue their child's participation at any time.

Confidentiality was strictly maintained. The primary investigator and research assistant were the only ones with access to identifying information. For the purpose of this study, the only identifying information collected was the child's first and last name and their date of birth. Children's date of birth are required in order to calculate chronological age, so that the standardized tests are scored appropriately. All participants were subsequently identified by an identification code, containing alphanumeric characters, not associated with any attributable similarity to the child's identification. These research identification codes were linked to the participants names via a master code list, kept secure and separate from the data collection forms. Upon 
competition of analysis, all assessment forms are being stored in a locked cabinet with restricted access. No identifying information of the participants will be released.

Parental and classroom instructor permission forms are likewise being kept in a locked cabinet, separate from the record forms to maintain confidentiality. These forms will be kept until the end of the 2015-16 academic year and then destroyed. Test record forms, data and video data will be shredded by December 31, 2016. 


\section{CHAPTER 4: RESULTS}

\section{Data Interpretation}

The primary purpose in utilizing the SP $2^{\mathrm{TM}}$ was to gain insight into the individual's sensory processing within the various context of everyday life. The purpose was not to compare individuals or isolate problematic patterns. The SP $2^{\mathrm{TM}}$, combined with other information collected through skilled observations, caregivers and school/health care professionals was useful in providing information which could be applied toward developing interventions that support the individual's sensory processing pattern in everyday life at home and in the school setting. The overall goal of this process is to improve quality of life.

This project used two methods to capture data about the application of TLC. Quantitative measurement of the child's sensory and behavioral performance was assessed with the SP $2^{\mathrm{TM}}$ questionnaire, from both the child's parent/caregiver and the classroom special education teacher. Qualitative measurement was performed by the researcher, and made by researcher observations at each of the twelve sessions, recording important instances of the child's physical interaction with the TLC device, as well as classroom and environmental dynamics that could have impacted the child's experience with use of TLC. Quantitative data (SP 2 ${ }^{\mathrm{TM}}$ ) was collected at two static points during the research period; prior to the initial application of TLC and upon completion of the twelve research sessions. Qualitative data was captured during each application session for each child. This combination of data inputs formed the body of information with which to assess the application of TLC in relation to the two research questions: 
1. In children with autism and auditory hypersensitivity, does application of TLC, compared to no application of TLC affect attentiveness during educational sessions?

2. In children with autism and auditory hypersensitivity, does application of TLC, compared to no application of TLC affect participation during educational sessions?

In order to analyze the information provided by the measurement tool, raw data was compiled into categorical generalizations, by use of the summary score sheet provided with the SP $2^{\mathrm{TM}}$ questionnaire from the pre- and post- evaluations. Examples of the summary score sheets are provided in Table 3.2 and Table 3.3. A spreadsheet was then prepared compiling the two sets of scores for each child, subsequently generating a side-by-side comparison of caregiver and teacher scorings (see Table 3.4, 3.5, 3.6 and 3.7). Following each of the twelve observed sessions, the qualitative data was similarly compiled into summations of all the important observed aspects of each application period. This resultant compilation became the basis from which the researcher could view trends, anomalies or exceptions and to facilitate and support conclusions.

The SP $2^{\mathrm{TM}}$ raw score data is represented as numbers, which indicate the relative position the question's response fell within the range of scores for each Likert category; they cannot be thought of as absolute scores, but relational in value. Also, while each category has its own range, that range is also different between the caregiver and the teacher questionnaires. For example, the Seeking category reporting range from the caregiver is $0-95$, whereas the teacher reporting range is $0-40$. It would be incorrect, therefore, to use the numbers in any correlation other than a relational position of the 
score with the range of scores in that Likert category. Because of the nature and relative briefness of this study, this researcher is using the resultant qualitative component of the questionnaire scores only as a means to apply the caregiver and teacher inputs in any observable trending of the child's sensory and behavioral changes during the evaluation period.

\section{Overall Descriptive Analysis}

As expected, each child is unique in where they were rated in each area. The first observation across all students is that there were no major changes between the pre- and post-scoring. As a general rule, in the majority of rating areas, each student either increased or decreased by a few points only. When there was a jump from one category to the other higher or lower, the scoring spread was normally from the middle of the preto the lower end of the post-, and the converse was also true. Each student had one or two rating areas where they individually had a larger margin of rating difference, either positively or negatively. No two students had the same rating swings in the same category.

What is consistently evident, by contrasting the caregiver and teacher responses, is the difference of scoring between the two. Less the $25 \%$ of the time the caregiver and teacher rated within the same category. Possible reasons for this will be discussed in the following chapter. While not conclusive by itself, the use of the SP $2^{\mathrm{TM}}$ measurement tool did provide a method in which to view subtle changes in a student's overall adaptation to the application of TLC, in a way that may not be visible during a session observation. During the observational sessions, there was no evidence presented that the students had an aversion to the wearing and use of the TLC device. Each student, after 
the initial fitting and audio level setting, appeared to be comfortable wearing the device as evidenced by not removing the device or indicating they wanted the device removed. Students F1 and M1, throughout the research session, exhibited characteristics of actually enjoying using the TLC device during the classroom instruction, as observed by greeting the researchers arrival and assisting with the application of TLC as standard expected protocol. As a side note, over the course of the data collection, other students in the classroom who were not study participants elected to wear sound muffling headphones available in the classroom in an effort to 'be like' the research subjects. Throughout the research, the subjects had to rise from their seats and move around the classroom; none of the subjects exhibited any trepidation or discomfort as they moved around freely.

In the case of F1 and M1, there was exposure to two unanticipated external noise events during the study period. The first one was a general fire alarm which was repeated twice due to a student pulling the fire alarm, resulting in elevated noise levels as the firefighters arrived at the school with sirens blaring. The second event involved a maintenance crew installing surveillance cameras on the roof directly over the classroom using hammers and drills. Surprisingly, neither of these instances hampered the use of TLC. In the fire alarm scenario, both students removed the device easily and quickly in order to evacuate the room. Upon the 'all clear' signal, the students twice returned to the classroom, re-applied TLC and continued with the lesson without hesitation. During the extremely noisy installation of the surveillance camera, both students appeared to pay no attention to the noise, while other students were significantly distracted, as evidenced by covering their ears in an attempt to reduce the noise. 
Students F2 and M2 exhibited a fascination with TLC, requiring the device to be placed out of sight or covered with a box during applications. Once they were no longer distracted by the novelty of the device, each student quickly returned their full attention to the classroom instruction. Student F2 was the only student in the research who appeared to change the volume of their voice in speaking while wearing the device. Her voice became increasingly louder, resulting in classroom disruption. In session \# 3 for this student, sidetone was added to the TLC device the student was using. Sidetone introduces some of the wearer's own voice back into the audio system, effectively reducing the muffling of one's voice that normal headphone usage can cause. After sidetone was introduced, student F2 immediately brought the loudness of her voice down to a normal level and it remained normal through the rest of the research period. 


\section{Individual Interpretation of Findings}

The following section describes each participant's findings with individually tabulated SP $2^{\mathrm{TM}}$ scoring results and descriptive analysis.

\section{Table 4.1: Student F1.}

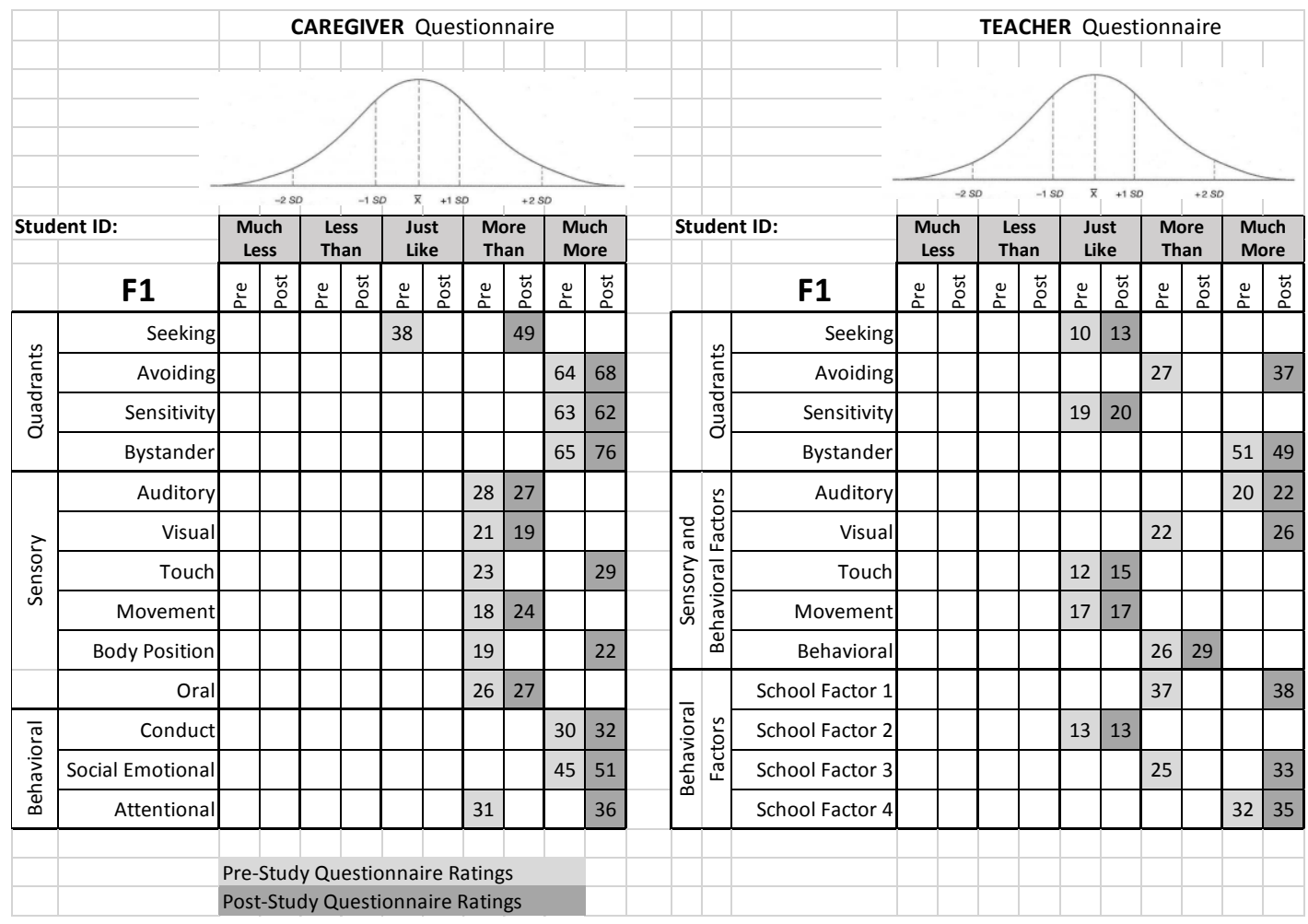

This female student, age 10, was similarly rated 'much more' in the quadrants of avoiding, sensitivity, and bystander by the caregiver in both the pre- and post-TLC application periods. The seeking quadrant increased from 'just like' to 'more than'. Sensory sections and behavioral sections were all scored in the 'more than' or 'much more' in both pre- and post-periods, with all sections fairly similar within a few points, with the exception of attentional increasing by 1 SD. According to Dunn (2014), attentional responses which are associated with sensory processing reflect the individual's ability to detect stimulation. This student was scored 'almost always' in 
attentional areas such as 'gets lost easily' and 'has a hard time finding objects in competing backgrounds'. Auditory processing was scored both pre- and post- in the 'more than' section with only a one point separation.

The classroom teacher scored F1 slightly lower in the seeking and sensitivity quadrant than the caregiver, but agreed with the bystander scoring in the 'much more' section. Avoiding behaviors were noted to increase in the post scoring. Auditory sensory processing, which measures the person's response to things heard or distractibility consistently stayed in the 'much more' section. Other measurements of sensory and behavioral factors remained consistent pre- and post- with the exception of visual, which increased from the 'more than' to the 'much more' column. This student wore both hearing aids and glasses until last year, when both were determined not necessary.

Additionally, three of the four school factors increased from pre- to post-scoring, which may indicate an increased teacher awareness of the student's need for additional support in the classroom. In F1's case, school factor 3 increased from 'more than' to 'much more'. This school factor is a reflection of the teacher's interpretation of the student's tolerance of change in routine or patterns and is additionally reflected in the increased teacher scoring pre- and post- in the area of avoiding behaviors. Avoiding behaviors include lack of group participation, difficulty in 'shifting gears', and time wasting for example.

Researcher observations of this student during the 12 sessions of the research process included that F1 consistently tolerated TLC and accepted the device as part of the normal classroom routine. Initially, when the device was applied and adjusted, the caregiver asked the child how she felt about the device. The child's response was "I like 
it. It makes me happy". It was observed that this child has difficulty with change, as noted on two occasions when there was a substitute teacher; her affect was noticeably flat on both occasions, but she did readily accept wearing the device and became more animated during application of TLC. F1 stayed on task while wearing TLC despite considerable environmental noise, both in the classroom and external noises (fire drill and maintenance crew on roof drilling and installing security cameras). School factor 4 also reflects F1's tendency to easily becoming overwhelmed, avoiding over-stimulation through disengagement and appearing unavailable for learning. An example of this on two occasions when a substitute teacher was present. F1 appeared withdrawn with no engagement with the classroom activity, limited eye contact and increased selfstimulating behaviors such as hand flapping and head shaking. These behaviors lessened upon application of TLC and the child engaged in the learning activity. 
Table 4.2: Student F2.

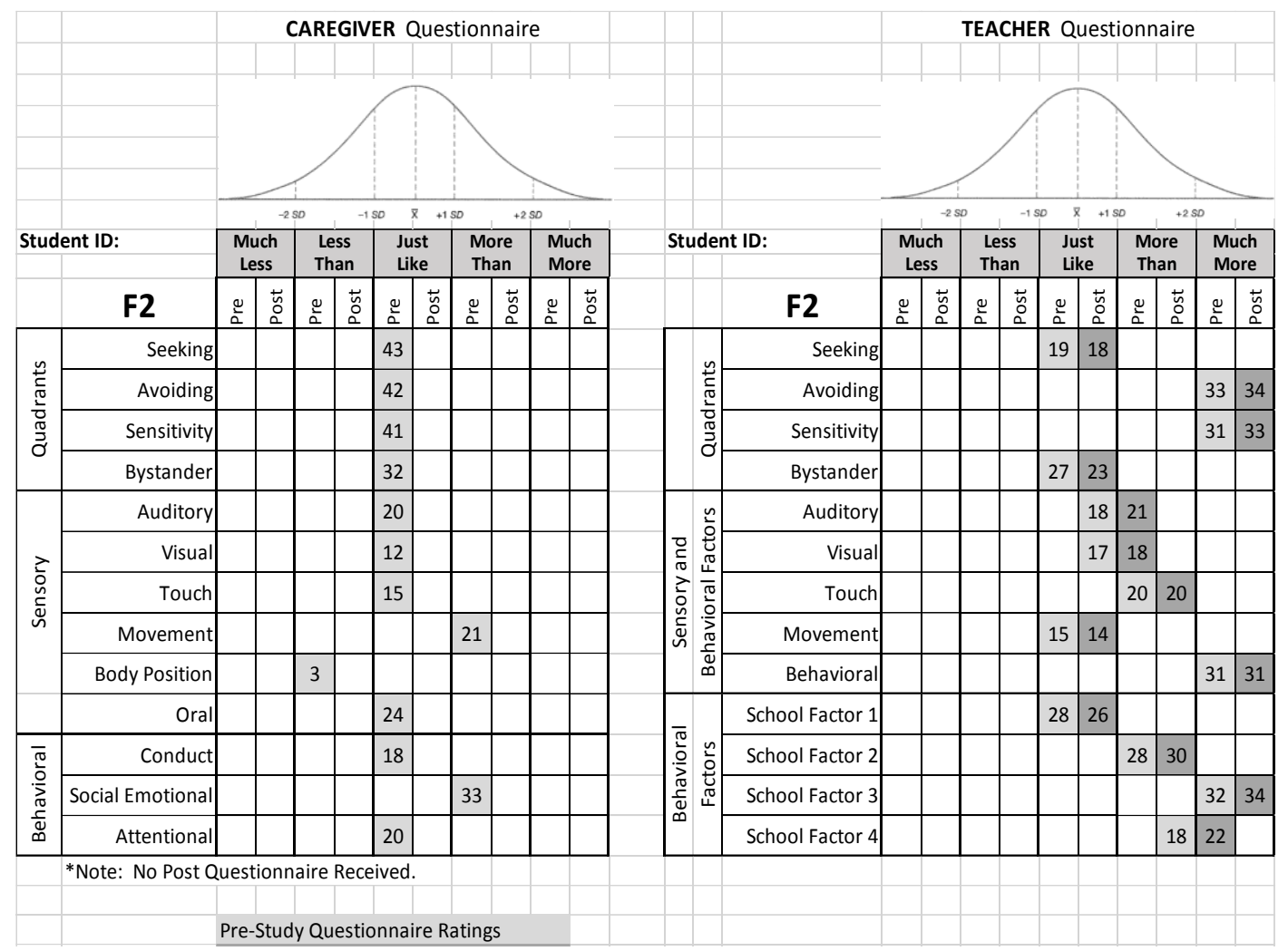

As the first general observation in the questionnaire comparisons, it appears that there is a difference in perception between the caregiver and teacher. In a majority of the questionnaire results, the two are reporting at least one category apart in several scoring areas. A probable reason for this may be that the caregiver is viewing the child in the home setting, with family and familiar surroundings, while the teacher is viewing the child in relation to classmates and the interactions commensurate with a classroom environment. F2's caregiver did not complete the final questionnaire. In the one questionnaire that was completed by the caregiver, all responses centered on 'just like others', however the teacher questionnaire showed significantly different observations. During the initial interview and hearing screening with F2, the caregiver commented how 
sensitive F2 was to sound and that noise cancelling earphones were commonly used in noisy public settings.

Teacher scoring remained fairly consistent in both pre- and post-scoring except in the area of auditory, which decreased from 'more than' to 'just like'. Seeking and avoiding quadrants scored slightly higher, as did three of the four school factors. F2 was observed to have great difficulties with change, as evidenced by emotional and behavioral outbursts in response to changes in the normal classroom routine which was extremely structured. On three occasions, a substitute teaching assistant was working with F2 one-on-one and the routine was slightly changed. On another occasion, F2 was extremely agitated because it was raining and raindrops had fallen on her face while walking to the classroom. These changes in the normal routine resulted in difficulties in F2's cooperating with the teacher as demonstrated by refusal behaviors and loud crying. On these occasions, the researchers were told by the classroom teacher that it was unsure whether F2 would be cooperative enough to apply TLC. However, on all occasions and throughout all 12 sessions, F2 never refused TLC application and would settle into the task at hand, either reading or math.

F2 was the student who required sidetone to regulate her voice level and would also fiddle with the headset and wires, which was a distraction to her learning. In addition to covering the TLC unit with a box, the wires were adjusted to run down the back of her chair and out of reach; this appeared to resolve the distraction. As noted, school factors 2, 3, and 4 increased post-scoring. School factor 2 relates to the student's attention and awareness of the learning environment. School factor 3 reflects the extent to which the student is distressed by changes in normal plans and routines. Individuals 
who rate high in the avoiding and sensitivity quadrants, such as F2, will attempt to limit their sensory input and will be reactive to environmental factors, demonstrating a low tolerance to sensory stimulation. School factor 4 relates to the student's availability to learn with a low threshold for regulatory patterns. Avoiders are easily overwhelmed, which makes them unavailable for learning. The teacher's scores are congruent with the researcher's observations. Despite several instances where change was noted in the classroom leading to an increase in avoiding and sensitivity behaviors, application of TLC was readily accepted and worn throughout the session without refusal. It was also noted that $\mathrm{F} 2$ would then focus on the learning process without further behavioral or emotional outbursts. The increased scoring in school factors 2,3 , and 4 may be related to increased classroom teacher awareness in behaviors and the need for additional classroom support. 
Table 4.3: Student M1.

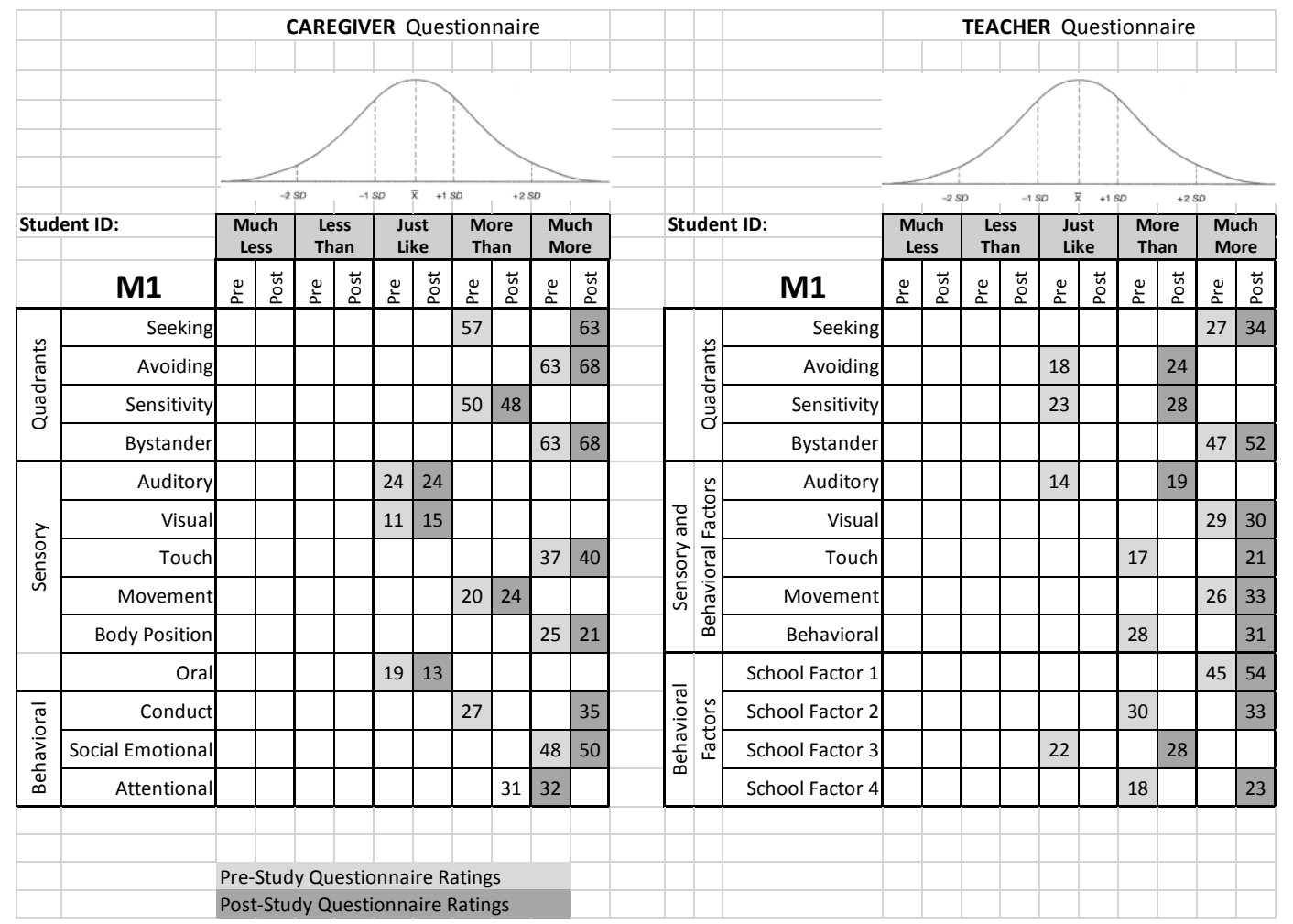

M1 was scored in the 'more than' or 'much more' categories in both the pre- and post-scoring in multiple quadrants by the caregiver and teacher. Both were in agreement that M1 had strong bystander tendencies, meaning that sensory cues were often missed or misinterpreted. Bystanders tend to be easy going with passive self-regulation. M1 was scored at the 'much more' level by the caregiver in avoiding behaviors while the teacher scored M1 higher in seeking behaviors. Children with 'much more' than others seeking patterns will use sensory input such as chewing pencils, tapping objects and touching to stay alert and gather information about their environment. According to Dunn (2014), each individual has a unique combination of scores representing patterns of behaviors. Also, every individual has some amount of each of the sensory patterns which adapt to various environmental situations. 
It is interesting to note on M1's caregiver and teacher pre- and post-scoring that with the exception of two scores (caregiver scoring of visual, movement and oral in the sensory category), all other post-scoring points were higher than the pre-scoring points, indicating sensory processing behaviors which, on the average, were 'more than' or 'much more' then, possibly indicating more of an awareness of sensory regulatory patterns as a result of completing the pre- and post-Sensory Profile $2^{\mathrm{TM}}$. The teacher scored M1's school factors in all four areas significantly higher in the post-scoring period, particularly in school factor 1 which reflects the students need for external supports to participate in the learning process. These results correlate with the identification of seeking and registration items scoring in the 'more than' and 'much more' then categories. M1 demonstrated patterns which were high threshold patterns of regulatory behavior and would be benefited by classroom supports with a lot of sensory input in order to maintain focus. TLC is an example of a support which provides sensory input that supports learner attentiveness and focus while decreasing external environmental distraction.

During the initial interview with the caregiver, she stated she does not like to take M1 to public places such as the grocery store or a movie as a 'melt down' will often occur. The caregiver also stated M1 usually wears headphones in public settings. This may be reflected in the pre- and post-caregiver scoring in the auditory section which remained unchanged. The teacher scoring of the auditory section, increased from 'just like' to the higher end of 'more than' on post scoring results. Neither the caregiver nor the teacher had a copy of the pre-scoring Sensory Profile $2^{\mathrm{TM}}$ to refer to when scoring the post-TLC application Sensory Profile $2^{\mathrm{TM}}$, as the initial questionnaires were collected by 
the researcher prior to the initial application of TLC. Therefore pre- and post-scores were separate scorings without comparison.

Table 4.4: Student M2.

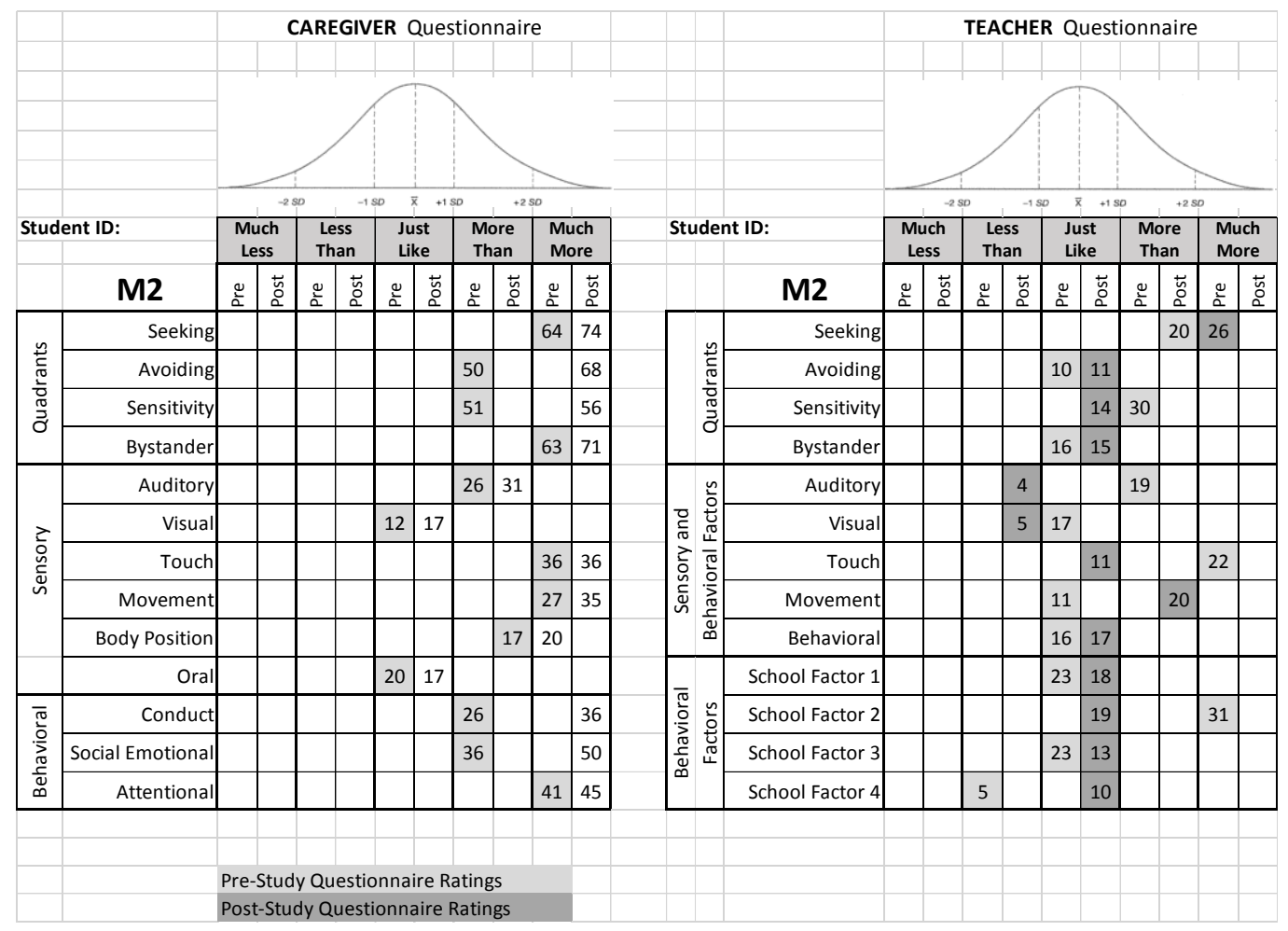

M2 also scored higher in multiple areas by the caregiver than by the teacher.

Most of the caregiver's scoring was in the 'more than' to 'much more' areas both preand post-, whereas the teacher's scoring both pre- and post- were mainly in the 'just like' columns. This variance may be due to the individual differences between the home and classroom environment. M2 was the eighth fostered/adopted child in a family of ten including the parents. The majority of the children in the family have special needs, several with severe handicaps. The special education classroom where $\mathrm{M} 2$ receives services and where the TLC application transpired was, in comparison, a more structured environment with less demands on M2 to exhibit self-regulatory behaviors. 
Both the caregiver and the teacher identified M2 with 'much more' to 'more than' seeking behaviors with touch and movement scoring above the 'just like' section; this was collaborated in the qualitative observations. M2 responded to kinesthetic learning such as copying letters on a chalkboard, counting small objects and using an extended plastic pointing finger on a numerical chart. Additionally, M2 would don a superhero cape when he was in a learning session, thus giving him 'superpowers' for learning. The superhero theme was incorporated into the teaching session. Skittles and 'high fives' were used as reward incentives which supported M2's need for touch and movement. While M2 responded well to kinetic learning, he was the most sensitive toward application of TLC. The headphones were a little too large for his head so when he would put his head forward they would tend to slide off. M2 also tended to fiddle with the wires, requiring the wires and the box to be out of site and not be a distraction. The teacher scored M2's auditory score significantly lower in the post-score in the 'less than' as compared to 'more than' in the pre-scoring.

In all four subjects, the students worked with both the special education teacher and the special education teacher's assistant who had specialized training with each specific student and followed individualized learning plans based on the student's Individual Education Plan. The special education teacher scored the SP $2^{\mathrm{TM}}$ forms in all subjects except M2's, in which the teacher and the teacher's assistance went over the form together, discussing the items and scoring the SP $2^{\mathrm{TM}}$ in front of the researcher. It was observed that M2 was much less distracted during the application of TLC and did not even turn his head when other students entered the classroom or noisy groups of children 
walked by the classroom. According to the teacher and teacher's assistant, this was a major concern that interfered with M2's attention and learning on a regular basis.

It was noted that in addition to auditory, multiple other areas including seeking, sensitivity, visual, and touch were rated lower post-scoring. School factors 1, 2, and 3 were lower in the post-scoring which relate respectively to the student's need for classroom supports. In particular, school factor 2 decreased from the 'much more' category to the 'just like' category, indicating the teacher's perception of the students awareness and attention within the learning environment was less of a factor. School factor 2 includes items relating to seeking and sensitivity behaviors in which the level of awareness and attentiveness can interfere with the learning process and ability to stay 'on task' during the learning session. School factor 3 is a measurement of the individual's reaction and tolerance to the learning environment. These individuals have low threshold sensory processing patterns and are often distressed and easily distracted by changes in plans or routines. In M2's case, school factor 3 decreased by 10 points from the upper end of 'just like the majority of others' to the lower end of 'just like the majority of others'. School factor 4 pre- and post-scoring increased from 'less than' to 'just like' indicating M2's availability for learning, participation and engagement with others in the learning environment had improved. School factor 4 is a measurement of behaviors associated with disengaged behavior resulting from input overstimulation. These individuals often appear unavailable for learning because they are overwhelmed and avoid environmental stimuli. Classroom modifications for these individuals would be those targeted toward decreasing environmental stimulation, such as TLC, in order to facilitate focus and attention on the learning task. 


\section{CHAPTER 5: OUTCOMES AND CONCLUSIONS}

\section{Project Observations}

The use of the Sensory Profile $2^{\mathrm{TM}}$ measurement tool was appropriate for this study, in that the scores from both pre- and post-study period provided the researcher with more information than just the primary measurement of beginning and after results. The different questionnaires also provided insight into the student's differing functional environments - school and home. As identified in the individual result discussion of the four cases, the home environment, as perceived by the caregiver, may be less about ontask behaviors and more on social interactions, whereas the school environment, as perceived by the teacher, is significantly more on-task behaviors and a lesser amount social interactions.

Qualitative observations made by the researcher during each session were invaluable in providing the other component of measurement. While the SP $2^{\mathrm{TM}}$ generally indicated behavioral and sensory trends or changes during the research period, the observations recorded each student's experience in using the TLC device through the specific activities and interruptions each session brought. Student participation in lessons, whether sitting down, standing up and moving about, was able to be visually studied for not only ease-of-use, but also for the safety and ergonomic aspects of wearing the TLC device as the student moved about in each activity.

Qualitative observations were also helpful in identifying certain characteristics of students while wearing noise-cancelling headphones in a classroom environment. Such was the case of one student (F2), where wearing headphones affected her ability to speak 
in a normal voice and led to her elevating her volume, subsequently disturbing the rest of the class. During the data collection process, this student was primarily involved in an individual activity with a Teacher Assistant (reading a book out loud, one-on-one math, etc.). The researcher was able to introduce sidetone on the TLC device, which then allowed the student to hear her own voice at a level sufficient to help her speak at the same volume as without headphones. By providing sidetone, a 'distraction' was resolved, thus allowing the student to resume normal classroom activities and continue participating in the research unhindered.

\section{Study Limitations/Recommendations}

The four students in this research study fell predominantly into two different age groups and as such, were at different levels of experience in the school setting. Two children in the $5^{\text {th }}$ grade (Students F1 and M1) both exhibited a certain maturity and experience in functioning in a classroom, while the other two children were much younger and therefore less mature and newer to the classroom environment. The maturity component manifested itself during the research period; namely whether the student viewed the TLC device as a learning tool to work with, or it was seen as a new 'toy' and not as a learning tool. During the course of the research period the researcher, in conjunction with and support of the teacher, was able to make 'modifications' to remove TLC from view and thereby allowing instruction to continue without further distraction.

These experiences and observations have afforded the researcher valuable input into the physical TLC device design and implementation. For younger aged students, a 
low-profile, out-of-view design for wearing would be more appropriate; once preferred noise and audio levels are set, there is no operational need to provide the student with a convenient distraction. For all students in the study, the headphone wire was a small but present issue in the student's movement. The older students simply dealt with it as they would when using headphones with their music player or other electronic device; however the younger students, who do not normally use such electronic devices, saw it as another piece of the novelty and hence a recurring distraction. It appears that the next logical step for use of such a device would be to connect the headphones wirelessly to the TLC device, thereby effectively removing chances of snagging or distraction.

Another limitation identified during the course of the study was that of headphone size. This study utilized Bose ${ }^{\mathrm{TM}}$ noise cancelling over-the-ear headphones, as they are both readily available and are the 'gold' standard in noise cancellation. The limiting factor is that Bose ${ }^{\mathrm{TM}}$ makes their headphones in one size - adult. Currently there are no child-size noise cancelling headphones on the market. The youngest study participant exhibited a bit of difficulty in keeping the headphones on when looking down at schoolwork or abruptly turning his head. With that being said, this student was also quick to put the headphones back on when it occurred and consistently displayed his enjoyment in using the TLC device.

The small sample size $(n=4)$ does not allow for any conclusions to be drawn from the study, but was arrived at after working closely with the school district's director of special education and special education teachers. Several students were initially identified in the school district as meeting the criteria for the research; however, after 
taking into account all factors, such as willingness or ability of parent or caregiver participation, etc., the selection ultimately arrived at the four students identified. Given the considerable time and expense in development of TLC to its current version, the study participant size was appropriate and achievable with the funds and resources available to allow for initial pilot study research.

\section{Conclusion}

To summarize the study results, feasibility knowledge was gained but not positive or negative results given the small sample size and relatively short study period. Each student participant, within their individual sensory, behavioral and educational continuums, exhibited a trend towards acceptance and perceived beneficial attributes while using TLC in the classroom. All participants were given full power to discontinue participation at any time for any reason; yet all appeared to embrace TLC as they moved through the study period.

While the four participant's response to the study and use of TLC is not representative of every student who could potentially benefit from the device, positive initial trending may support further study. Additional studies could be expanded to various populations outside of those with ASD, who also suffer from hyperacusis. Some examples could be children with prenatal drug exposure, Attention Deficit Disorder, Sensory Processing Disorders, etc. The bulk of current research on hyperacusis and sound therapy has been done by health professionals in the fields of Communication Disorders and Psychology. A multidisciplinary approach including Doctor of Nursing Practice prepared nurses, School Nurses, Occupational Therapists and Educational 
professionals in the field of Special Education would benefit existing research, while providing varied but correlated therapeutic methodologies. As discussed, further refinement is the next step in the evolution of TLC. Following this developmental process, a focused-study with a larger sample size over a longer period of time in varied learning environments would provide significantly more data points to better access the effectiveness of TLC. 


\section{References}

Aazh, H., McFerran, D., Richard, S., Deepak, P., Jastreboff, M., \& Jastreboff, P. (2014). Insights from the first international conference on hyperacusis: Causes, evaluation, diagnosis and treatment. Noise \& Health, 16(69), 123-126. http://dx.doi.org/10.4103/1463-1741.132100

Aazh, H., Moore, B., \& Prasher, C. (2011). Providing support to school children with hyperacusis. British Journal of School Nursing, 6, 174-178.

Alcantara, J. I., Weisblatt, E. J., Moore, B. C., \& Bolten, P. F. (2004). Speech-in-noise perception in high-functioning individuals with autism. Journal of Child Psychology and Psychiatry, 45, 1107-1114.

American National Standard Acoustical Performance Criteria, Design Requirements and Guidelines for Schools. (2002). Retrieved from www.asha.org

Boushey, A. (2001). The grief cycle - One parent's trip around. Focus on Autism and Other Developmental Disabilities, 16(1), 27-30.

Centers for Disease Control and Prevention: Data \& Statistics. (2015). Retrieved from http://www.cdc.gov/ncbddd/autism/research.html

Clarke, P. N., Barone, S. H., Hanna, D., \& Senesac, P. M. (2011). Roy’s adaptation model. Nursing Science Quarterly, 24(4), 337-344. Retrieved from http://dx.doi.org/10.1177/0894318411419223

Cook, A., Bradley-Johnson, S., \& Johnson, C. (2014). Effects of white noise on off-task behavior and academic responding for children with ADHD. Journal of Applied Behavioral Analysis, 47(1), 160-164. 
Corbett, B., \& Constantine, L. (2006). Autism and attention deficit hyperactivity disorder: Assessing attention and response control with the integrated visual and auditory continuous performance test. Child Neuropsychology, 12, 335-348.

Corbett, B., Shickman, K., \& Ferrer, E. (2008). Brief Report: The effects of tomatis sound therapy on language in children with autism. Journal of Autism and Developmental Disorders, 38, 562-566. http://dx.doi.org/10.1007/s10803-0070413-1

Crandell, C., Smaldino, J., \& Flexer, C. (2005). Sound field amplification: Applications to speech perception and classroom acoustics ( $2^{\text {nd }}$ ed.). Clifton Park, NY: Thomson Delmar Learning.

Duchan, E., \& Patel, D. R. (2012). Epidemiology of autism spectrum disorders. Pediatric Clinical of North America, 59, 27-43. http://dx.doi.org/10.1016/j.pcl.2011.10.003

Dunn, W. (2014). NCS Pearson Inc. [Sensory Profile-2 ${ }^{\mathrm{TM}}$ ]. Published instrument. Retrieved from www.PearsonClinical.com

Dunn, W. (2014). Sensory Profile 2: User's Manual - Strength Based Approach to Assessment and Planning. Bloomington, NY: PsychCorp.

Engineer, N. E., Riley, J. R., Steele, J. D., Shetake, W. A., Sudanagunta, J. A., \& Kilgard, M. P. (2011, February 3). Reversing pathological neural activity using targeted plasticity. Nature, 375, 21-34.

Frederickson, K., Acuna, V. R., Whetsell, M., \& Tallier, P. (2005). Cross-cultural analysis for conceptual understanding: English and Spanish perspectives. Nursing Science Quarterly, 18(4), 286-292. 
Gerritsen, J. (2008). Response to "Brief report: The effects of tomatis sound therapy on language in children with autism". Journal of Autism and Developmental Disorders, 38, 567. http://dx.doi.org/10.1007/s10803-007-0471-4

Gomes, E., Rotta, N. T., Pedroso, F. S., Sleifer, P., \& Danesi, M. C. (2004). Auditory hypersensitivity in children and teenagers with autistic spectrum disorder. Arq Neuropsiquiatr, 62(3-B), 797-801.

Groen, W. B., Van Orsouw, L., Ter Huurne, N., Swinkels, S., Van der Gaag, R., Buitelaar, J. K., \& Zwiers, M. P. (2009). Intact spectral but abnormal temporal processing of auditory stimuli in autism. Journal of Autism Developmental Disorders, 39, 742-750. http://dx.doi.org/10.10007/s10803-008-0682-3

Hallmayer, J., Cleveland, S., Torres, A., Phillips, J., Cohen, J., Torigoe, T., \& Fedele, A. (2011). Genetic heritability and shared environmental factors among twin pairs with autism. Archeology of General Psychiatry, 68(11), 1095-1102.

Helps, S. K., Bamford, S., Sonuga-Barke, E. J., \& Soderlund, G. B. (2014, November 13). Different effects of adding white noise on cognitive performance of sub-, normal and super-attentive school children. PLOS One. http://dx.doi.org/10.1371/journal.pone.0112768

Helson, H. (1964). Adaptation level theory. New York: NY: Harper \& Row.

Hyche, K., \& Maertz, V. (2014). Classroom strategies for children with ADHD, Autism and Sensory Processing Disorders: Solutions for Behavior, Attention and Emotional Regulation. PESI Publishing \& Media.

Johnston, K. N., John, A. B., Kreisman, N. V., Hall, J. W., \& Crandell, C. C. (2009). Multiple benefits of personal FM system use by children with auditory processing 
disorder (APD). International Journal of Audiology, 48, 371-383.

http://dx.doi.org/10.1080/14992020802687516

Juris, L., Andersson, G., Larsen, H., \& Ekelius, L. (2014). Cognitive behavior therapy for hyperacusis: A randomized controlled trial. Behavioral Research and Therapy, 54(), 30-37. http://dx.doi.org/10.1016/j.brat.2014.01.001

Levitin, D., Cole, K., Lincoln, A., \& Bellugi, U. (2005). Aversion, awareness, and attraction: Investigating claims of hyperacusis in the Williams's syndrome and phenotype. Journal of child Psychology Psychiatry, 45, 514-523.

Loh, W., Yegnanarayanan, S., Ram, R., \& Juodawlkis, P. (2013), United theory of oscillator phase noise ii: Flicker noise. IEEE Transitions on Microwave Theory \& Techniques, 61(12), 4130-4144. http://dx.doi.org/

Lucker, J. R. (2013). Auditory hypersensitivity in children with autism spectrum disorders. Focus on Autism and Other Developmental Disabilities, 28(3), 184191. http://dx.doi.org/10.1177/1088357613475810

Magana, S., Parish, S. L., Roderick, R. A., Timberlake, M., \& Swaine, J. G. (2012). Racial and ethnic disparities in quality of health care among children with autism and other developmental disabilities. Intellectual and Developmental Disabilities, 50(4), 287-299. http://dx.doi.org/10.1352/1934-9556-50.4.287

Maloret, P., \& Sumner, K. (2014). Understanding autism spectrum conditions. Learning Disability Practice, 17(6), 23-26.

Morrier, M. J., \& Hess, K. L. (2012). Ethnic differences in autism eligibility in the United States public schools. The Journal of Special Education, 46(1), 49-63. http://dx.doi.org/10.1177/0022466910372137 
Munro, K., \& Blount, J. (2009). Adaptive plasticity in brainstem of adult listeners following earplug-induced deprivation. J Acoustic Soc Am, 126, 586-571.

Norena, A. J., \& Chery-Crose, S. (2007). Enriched acoustic environment rescales auditory sensitivity. NeuroReport, 18, 1251-1255.

Norena, R. J. (2011). An integrative model of tinnitus based on a central gain controlling neural sensitivity. Neuroscience and Biobehavioral Reviews, 35, 1089-1109.

Parrish, R. N. (2010). Mother' experiences raising children who have multiple disabilities and their perceptions of the chronic sorrow phenomenon (Doctoral dissertation). Retrieved from http://www.proguest.com.hmlproxy.lib.cuufresno.edu/enUS/products/dissertations/individuals.shtml.

Pienkowski, M., Tyler, R. S., Roncancio, E. R., Jun, H. J., Brozoski, T., Dauman, N., \& Coelho, C. B. (2014). A review of hyperacusis and future directions: Part II. Measurement, mechanisms, and treatment. American Journal of Audiology, 23, 420-436. http://dx.doi.org/10.1044/2014_AJA-13-0037

Porges, S. W., Bazhenova, O. V., Bal, E., Carlson, N., Sorokin, Y., Heilman, K. J., ... Lewis, G. F. (2014). Reducing auditory hypersensitivities in autistic spectrum disorder: Preliminary findings evaluating the listening project protocol. Frontiers in Pediatrics, 2(80). http://dx.doi.org/10.3389/fped.2014.00080

Rosenhouse, G. (2014). The spectral effect of masking of intruding noise by environmental background-noise. The Journal of the Acoustical Society of America, 135(4), 23-43. 
Roy, C. (1970). Adaptation: A conceptual framework for nursing. Nursing Outlook, $18(3), 18-23$.

Roy, C. (1976). Introduction to nursing: An adaptation model. Englewood Cliffs, NJ:

Prentice Hall.

Roy, C. (2009). The Roy Adaptation model (3rd ed.). Upper Saddle River: NJ: Pearson Education.

Roy, C. (2014). Generating middle range theory: From evidence to practice. New York City, NY: Springer Publishing Company.

Salvi, R., Wang, J., \& Ding, D. (2000). Auditory plasticity and hyperactivity following cochlear damage. Hearing Research, 147, 261-274.

Stiegler, L. N., \& Davis, R. (2010). Understanding sound sensitivity in individuals with autism spectrum disorder. Focus on Autism and Other Developmental Disorders, 25(2), 67-75. http://dx.doi.org/10.1177/108357610364530

Thurgate, C., \& Warner, H. (2005). Living with disability: Part 1. Pediatric Nursing, 17(10), 37-42.

Tomchek, S. D., \& Dunn, W. (2007). Sensory processing in children with and without autism: A comparative study using the short sensory profile. American Journal of Occupational Therapy, 61, 1990-200.

Tyler, R. S. (2012). Patient preferences and willingness to pay for tinnitus treatment. Journal of the American Academy of Audiology, 23, 115-125.

Tyler, R. S., Coelho, C., Tao, P., Noble, W., Haskell, C., \& Bardia, A. (2008). Identifying tinnitus subgroups with cluster analysis. American Journal of Audiology, 17, 176184. 
Tyler, R. S., Gehringer, A. K., Noble, W., Dunn, C. C., Witt, S. A., \& Bardia, A. (2006). Tinnititus Activities Treatment: In R.S. Tyler (Ed.) Tinnititus Treatment: Clinical Protocols. New York: NY: Thieme Medical.

U.S. Department of Health and Human Services. (2015). http://www.hhs.gov/news/press/2014pres/05/20140501a.html

Von Bertalanffy, L. (1968). General system theory. New York, NY: George Braziller. Wang, Y., \& Ren, C. (2012). Effects of repeated "benign” noise exposures in young CBA mice: Shedding light on age-related hearing loss. Journal of the Association for Research in Otolaryngology, 13, 505-515.

Whetsell, M. V., Gonzalez, Y. M., \& Moreno-Fergusson, M. (2015). Models and theories focused on a systems approach. In J. B. Butts, \& K. L. Rich (Eds.), Philosophies and theories for advanced nursing practice (2nd Edition ed., pp. 407-434). Burlington, MA. James \& Bartlett Learning.

Young, L. B. (1986). The unfinished universe. New York: Simon \& Schuster.

Zablotsky, B., Black, L., Maenner, M. J., Schieve, L. A., \& Blumberg, S. J. (2015). Estimated prevalence of autism and other developmental disabilities following questionnaire changes in the 2014 national health interview survey (87). Retrieved from U.S. Department of Health and Human Services: Centers for Disease Control and Prevention; National Center for Health Statistics: www.CDC.gov 


\section{Appendix A}

\section{Sensory Profile 2 ${ }^{\mathrm{TM}}$ Category Definitions:}

The Sensory Profile 2 questionnaire has questions that correspond with measurement categories. The categories are listed below with a brief explanation each, as presented in the manual:

\section{Sensory Processing Pattern Scores (Quadrant Scores)}

Seeking The degree to which a child obtains input. The items measure the person's interest in and pleasure with sensation (e.g., craves certain food, tastes or smells).

Avoiding The degree to which a child is bothered by sensory input. The items measure the person's need for controlling the amount and type of sensations available at any time (e.g., holds hands over ears to protect from sound).

Sensitivity The degree to which a child detects sensory input. The items measure the person's awareness of sensation available (e.g., is a picky eater, especially about food textures).

Registration The degree to which a child misses sensory input. The items measure the person's awareness of sensation (e.g., seems oblivious to messy hands or face).

\section{Sensory System Scores}

General Processing These items measure the person's broad sensory processing (e.g., has an unpredictable sleep pattern).

Auditory Processing These items measure the person's responses to things heard. (e.g., is distracted when there is a lot of noise around).

Visual Processing Includes items that measure the person's responses to things seen (e.g., leaves item blank on busy worksheet despite knowing the answers).

Touch [Somatosensory] Processing Measures the person's responses to stimuli that touch the skin (e.g., pulls at clothing or resists getting clothes on).

Movement [Vestibular] Processing Measures the person's responses to movement (e.g., loses balance unexpectedly when walking on an uneven surface).

Body Position [Proprioceptive] Processing Measures the person's responses to changes in joint and muscle positions (e.g., becomes tired easily, especially when standing or holding the body in one position).

Oral Sensory Processing Measures the person's responses to touch and taste in the mouth (e.g., enjoys making movements or sounds with mouth). 
Sensory Processing Provides an overall indication of a person's responses to sensory interactions and is designed to give quick information for screening and research purposes.

\section{Behaviors Associated With Sensory Processing Scores}

Conduct measures the person's responses to expectations (e.g., rushes through coloring, writing or drawing).

Social Emotional measures the person's expressiveness (e.g., has strong emotional outbursts when unable to complete a task).

Attentional responses measures the person's ability to detect important stimuli (e.g., jumps from one thing to another so that it interferes with activities).

\section{School Factor Scores}

School Factor 1 Reflects the student's need for external supports to participate in learning (e.g., struggles to keep materials and supplies organized for use during the day).

School Factor 2 Reflects the student's awareness and attention within the learning environment.

School Factor 3 Reflects the student's tolerance within the learning environment (e.g., distressed by changes in plans, routines or expectations).

School Factor 4 Reflects the student's availability for learning within the learning environment (e.g., interacts or participates in groups less than same-aged students).

From: Dunn, W. (2014). Sensory Profile 2: User's Manual - Strength Based Approach to Assessment and Planning. Bloomington, NY: PsychCorp. Reprinted with permission. 


\section{APPENDIX B}

\section{Pearson's Product Permission to Copyright Letter}
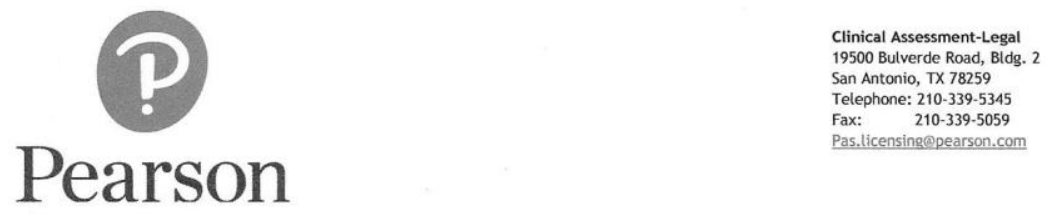

February 21, 2016

California State University Fresno

C/o Professor Jennifer M. Hughes, Doctoral Candidate

107 Picadilly Lane

Grass Valley, CA 95949

Re: Sensory Profile 2 (the "Product")

Dear Professor Hughes:

Thank you for your request for permission to use “Dunn's Sensory Processing Framework” Figure 2.1, and several descriptive text and figures from the Product Manual and other forms for your reproduction and Use as a part your research project paper to more fully describe the Product (the "Use").

We have no objection to the use of this material for the purpose as stated above subject to the following Terms and Conditions:

1. You have permission to Use the following items in your research project as follows:

a. Dunn's Sensory Processing Framework" Figure 2.1

b. Child Sensory Profile 2 normal curve and classification system table with associated distribution curve found on page 8 on the Child Sensory Profile 2 Caregiver Questionnaire.

c. Vocabulary definitions of sensory processing pattern scores (quadrant scores), sensory system scores (sensory sections), behaviors associated with sensory processing scores (behavioral sections) and school factor scores from page 20-23 Product manual.

2. This permission expires February 28,2018 . Further permission must be separately requested.

3. Please note the following copyright and trademark notice(s):

Sensory Profile ${ }^{\text {th }}$ 2. Copyright (c) 2014 NCS Pearson, Inc. Reproduced with permission. All rights reserved.

"Sensory Profile" is a trademark, in the US and/or other countries, of Pearson Education, Inc. or its affiliates(s).

Sincerely,

William H. Schryver

William H. Schryver

Senior Legal Licensing Specialist

ALWAYS LEARNING 